\title{
Hippocampal Somatostatin Interneurons, Long-Term Synaptic Plasticity and Memory
}

\author{
Eve Honoré, Abdessattar Khlaifia, Anthony Bosson and Jean-Claude Lacaille*
}

Department of Neurosciences, Centre for Interdisciplinary Research on Brain and Learning, Research Group on the Central Nervous System, Université de Montréal, Montreal, QC, Canada

A distinctive feature of the hippocampal structure is the diversity of inhibitory interneurons. These complex inhibitory interconnections largely contribute to the tight modulation of hippocampal circuitry, as well as to the formation and coordination of neuronal assemblies underlying learning and memory. Inhibitory interneurons provide more than a simple transitory inhibition of hippocampal principal cells (PCs). The synaptic plasticity of inhibitory neurons provides long-lasting changes in the hippocampal network and is a key component of memory formation. The dendrite targeting interneurons expressing the peptide somatostatin (SOM) are particularly interesting in this regard because they display unique long-lasting synaptic changes leading to metaplastic

OPEN ACCESS

Edited by:

Maria Gutierrez-Mecinas, University of Glasgow,

United Kingdom

Reviewed by:

Rebecca Ann Piskorowski, INSERM U1266 Institut de Psychiatrie et Neurosciences de Paris, France Marco Fuenzalida, Universidad de Valparaiso, Chile

*Correspondence:

Jean-Claude Lacaille jean-claude.lacaille@umontreal.ca

Received: 29 March 2021 Accepted: 30 April 2021

Published: 02 June 2021

Citation:

Honoré E, Khlaifia A, Bosson A and Lacaille J-C (2021) Hippocampal

Somatostatin Interneurons, Long-Term Synaptic Plasticity and Memory.

Front. Neural Circuits 15:687558. doi: 10.3389/fncir.2021.687558 regulation of hippocampal networks. In this article, we examine the actions of the neuropeptide SOM on hippocampal cells, synaptic plasticity, learning, and memory. We address the different subtypes of hippocampal SOM interneurons. We describe the longterm synaptic plasticity that takes place at the excitatory synapses of SOM interneurons, its singular induction and expression mechanisms, as well as the consequences of these changes on the hippocampal network, learning, and memory. We also review evidence that astrocytes provide cell-specific dynamic regulation of inhibition of PC dendrites by SOM interneurons. Finally, we cover how, in mouse models of Alzheimer's disease (AD), dysfunction of plasticity of SOM interneuron excitatory synapses may also contribute to cognitive impairments in brain disorders.

Keywords: somatostatin, inhibitory interneuron, hippocampus, network metaplasticity, long-term potentiation, spatial and contextual memory, memory impairment, Alzheimer's disease

\section{INTRODUCTION}

Hippocampal learning and memory emerge from the proper routing of information throughout its networks and the formation of enduring neuronal assemblies encoding a memory (Kandel et al., 2014). These neuronal assemblies, also called engrams, are formed by a discrete population of excitatory glutamatergic principal cells (PCs) between which synaptic transmission is potentiated (Josselyn and Frankland, 2018; Tonegawa et al., 2018).

A distinctive feature of the hippocampal structure is the diversity of inhibitory interneurons. PCs represent the majority of neurons in every hippocampal region. While interneurons 
only represent 10 to $20 \%$ of the total neuron population, they can be divided into many subgroups based on their laminar position, dendritic and axonal morphology, protein expression, electrophysiological features, and functions (Freund and Buzsáki, 1996; Somogyi and Klausberger, 2005; Tricoire et al., 2011; Kepecs and Fishell, 2014; Pelkey et al., 2017; Booker and Vida, 2018). Interestingly, the different interneuron types have preferred synaptic connections on specific and distinct subcellular domains of the principal cells including the apical and proximal dendrites, cell body, and the axon initial segment. Due to their specific characteristics, inhibitory interneurons play various roles in fine-tuning signal integration and firing of PCs. Additional levels of control of the hippocampal network is achieved by interneurons targeting other interneurons (Katona et al., 1999; Pelkey et al., 2017; Artinian and Lacaille, 2018) along with interneuron-astrocyte interactions (Mederos and Perea, 2019).

These complex inhibitory interconnections largely contribute to the tight modulation of hippocampal circuitry, providing means for the formation and coordination of neuronal assemblies. Hence, hippocampal interneurons also participate in the mechanisms underlying hippocampus-dependent memory. In this review, we aim to shed light on a major subpopulation of GABAergic interneurons specifically inhibiting PC dendrites and characterized by the expression of the peptide somatostatin (SOM). As the morphological and neurochemical profiles of these interneurons have already been reviewed (Pelkey et al., 2017; Booker and Vida, 2018), we will focus on the role of SOM interneuron activity and synaptic plasticity in the regulation of hippocampal networks and memory functions.

\section{SOMATOSTATIN IN THE HIPPOCAMPUS}

The peptide SOM, also referred as somatotropin release inhibitory factor (SRIF), was originally discovered in the hypothalamus where it acts as a growth hormone inhibitor (Krulich et al., 1968; Brazeau et al., 1973). In the cerebral cortex, SOM is stored in dense-core vesicles in a specific subset GABAergic interneurons and released by intense neuronal activity (Vezzani et al., 1993; Hou and Yu, 2013; Liguz-Lecznar et al., 2016). SOM can bind to five metabotropic receptors $\left(\mathrm{SST}_{1-5} \mathrm{R}\right)$ which are coupled to $\mathrm{G}$ protein from the $\mathrm{Gi} / \mathrm{o}$ and Gq/G11 families. Thus, SSTR activation downregulates adenylyl cyclase activity and activates the phosphoinositide 3-kinase and phospholipase C $\beta$ signaling pathways (Liguz-Lecznar et al., 2016; Günther et al., 2018). $\mathrm{SST}_{1-4} \mathrm{R}$, but not $\mathrm{SST}_{5} \mathrm{R}$, are present in the hippocampus in PCs and as auto-receptors in SOM interneurons. Although the distribution of SSTRs overlaps within and across hippocampal regions, SSTR subtypes preferentially occupy specific cell compartments. $S_{S T} R$ are preferentially located pre-synaptically, $\mathrm{SST}_{2} \mathrm{R}$ and $\mathrm{SST}_{4} \mathrm{R}$ post-synaptically, and $\mathrm{SST}_{3} \mathrm{R}$ extra-synaptically. Yet, which cell type expresses the receptors and whether they are pre or postsynaptic remains unclear (Csaba and Dournaud, 2001; Liguz-Lecznar et al., 2016; Cammalleri et al., 2019).

The systematic distribution of SSTRs suggests a precise regulation of hippocampal networks by SOM. However, the mechanisms by which SOM regulates hippocampal networks remain ambiguous. Reports of membrane and synaptic effects are diverse and sometimes contradictory. On the one hand, SOM has an inhibitory effect on pyramidal neurons exhibiting hyperpolarizing effect, decreasing evoked and spontaneous activity, persistently reducing NMDA and AMPA currents, and reducing spine density (Pittman and Siggins, 1981; Tallent and Siggins, 1997; Hou and Yu, 2013). On the other hand, SOM also produces excitatory effects on pyramidal cells inducing membrane depolarization, as well as increasing spontaneous and evoked excitatory postsynaptic potentials (EPSPs; Olpe et al., 1980; Delfs and Dichter, 1983; Scharfman and Schwartzkroin, 1988, 1989).

Many factors may explain these discrepancies. First, in many studies, the effect of SOM is concentration-dependent, and the number of PCs responding to SOM application with a depolarization follows an inverted U-shaped curve between $100 \mathrm{pM}$ and $1 \mu \mathrm{M}$, until it reaches potent toxic concentrations over $10 \mu \mathrm{M}$ (Olpe et al., 1980; Pittman and Siggins, 1981; Delfs and Dichter, 1983; Scharfman and Schwartzkroin, 1988; Tallent and Siggins, 1997). Second, the location of SOM application is also important. In rabbit hippocampal slices, SOM application on the soma of CA1 PCs induces membrane depolarization often accompanied by action potentials. When applied on the dendrites of PCs SOM produces depolarization or hyperpolarization. Larger SOM applications further away from PCs induce membrane hyperpolarization (Scharfman and Schwartzkroin, 1988). Third, inhibitory interneurons also express SSTRs. SOM application at the soma of interneurons at the border between stratum pyramidale and oriens produces a depolarization accompanied by an action potential in these cells. When applied at their dendrites, SOM produces either depolarization followed by increased action potentials, or hyperpolarization also followed by increased action potentials, or a combination of depolarization and action potential discharge followed by a hyperpolarization (Scharfman and Schwartzkroin, 1988).

The effect of SOM on interneuron output also appears complex. Blocking $\mathrm{SST}_{1} \mathrm{R}$ resulted in an increase in SOM concentration but had no effect on GABA concentration in vivo (De Bundel et al., 2010). This finding may indicate that SOM release from an interneuron can promote auto-inhibition via $\mathrm{SST}_{1} \mathrm{R}$ presynaptic activation without interfering with GABA transmission. Bath application of somatostatin did not affect isolated GABAergic inhibitory postsynaptic currents induced by stimulation close to the pyramidal cell layer, nor the density of inhibitory synapses (Tallent and Siggins, 1997; Hou and $\mathrm{Yu}, 2013)$. However, earlier research demonstrated persistent reduction or blockade of spontaneous or evoked inhibitory postsynaptic potentials (Pittman and Siggins, 1981; Scharfman and Schwartzkroin, 1988, 1989).

Finally, another level of complexity with SOM effects arises from its long-lasting action. SOM produces long-lasting increases in spontaneous activity and evoked responses of pyramidal cells via postsynaptic effects (Delfs and Dichter, 1983; Scharfman and Schwartzkroin, 1988). In addition, transgenic mice with ablation of the SOM gene or mice with pharmacological depletion of 
SOM by cysteamine treatment, have normal basal transmission but a deficit in long-term potentiation (LTP) in CA1 (Kluge et al., 2008). Taken altogether this corpus of data suggests that SOM has a complex function which is dependent on the location and concentration released, the activated receptor subtype, and experimental conditions (for details see Table 1).

Interestingly, at the behavioral level, SOM appears important as a neuromodulator of hippocampal function. Genetic ablation of the SOM gene or SOM depletion by cysteamine impairs contextual fear memory and has no effect on cued fear memory, indicating a specific action on hippocampus-dependent memory (Kluge et al., 2008). Moreover, intracerebroventricular injection of SOM, or a non-hydrolyzable SOM analog, before or after learning, increases active and passive avoidance behaviors $24 \mathrm{~h}$ after the acquisition and prevents their extinction (Vécsei and Widerlöv, 1988; Vécsei et al., 1989). However, both treatments have no effect on spatial discrimination learning and reversal learning in the T-maze test (Vécsei et al., 1984). Again, SOM concentration is critical, low concentrations increase passive avoidance memory, while 10-fold higher concentrations have the opposite effect (Vécsei et al., 1984, 1989; Vécsei and Widerlöv, 1988; Schettini, 1991). Pre-training intra-hippocampal injection of $\mathrm{SOM}$ or a $\mathrm{SST}_{4} \mathrm{R}$ agonist impairs spatial memory in a dose-dependent manner. In addition, the $\mathrm{SST}_{4} \mathrm{R}$ agonist decreases cued memory and enhances the retention of bar pressing tasks. Intriguingly, the administration of $\mathrm{SST}_{1-3} \mathrm{R}$ agonists does not evoke any behavioral change (Gastambide et al., 2008). The timing of SOM treatment is also critical. When injected before the memory acquisition trials in the 8-arm radial maze task, SOM increases acquisition rates. However, when administered before the memory probe test, it impairs performance. Thus, SOM has different effects on acquisition and memory probe tests (Guillou et al., 1993; Lamirault et al., 2001). Finally, it is important to note that hippocampal injections of $\mathrm{SOM}$ or agonists of $\mathrm{SST}_{4} \mathrm{R}$ and $\mathrm{SST}_{2} \mathrm{R}$ have anxiolytic and antidepressant-like effects via the inhibition of the hypothalamicpituitary-adrenal axis. Through this mechanism, SOM also regulates emotions and stress responses which strongly modulate learning and memory (Prévôt et al., 2017; for details see Table 2).

Thus, at the behavioral level, SOM is required for proper memory formation. The location, timing, and concentration of SOM release by interneurons appears crucial for SOM functional outcomes, perhaps because of the distribution and types of receptors involved. However, a better understanding of how, where and when SOM is released to fulfill its functions requires new precise tools.

\section{HIPPOCAMPAL SOMATOSTATIN INTERNEURONS}

Although hippocampal interneurons release the peptide SOM, in hippocampal research this peptide has largely been regarded as a neurochemical marker for a subset of GABAergic interneurons. Through their GABAergic actions, SOM interneurons provide local inhibition to regulate hippocampal networks, and distal inhibition to synchronize hippocampal activity with other brain areas. Hippocampal SOM interneurons have been the subject of recent comprehensive reviews (Muller and Remy, 2014; Pelkey et al., 2017; Booker and Vida, 2018). Thus, they gate the synaptic inputs of their targets (Katona et al., 1999; Muller and Remy, 2014). SOM interneurons preferentially receive excitatory inputs from local PCs to which they send inhibitory feedback (Lacaille et al., 1987; Blasco-Ibáñez and Freund, 1995). Yet, there is more to SOM interneuron function than negative feedback. SOM interneurons dynamically regulate the inputoutput transformation and firing of PCs both in slices and during exploration in vivo (Lovett-Barron et al., 2012; Royer et al., 2012). In addition, SOM interneurons are diverse, and each type has a different contribution to the regulation of information flow through PCs (Figure 1).

\section{Oriens Lacunosum-Moleculare (OLM) Cells}

OLM cells are the most extensively studied SOM interneurons in the hippocampus. They are located in CA3 and CA1 along the complete dorso-ventral axis of the hippocampus (Mikulovic et al., 2015). Their designation comes from the location of their soma and dendrites in stratum oriens and their rich axonal arborization in stratum lacunosum-moleculare (Lacaille et al., 1987; Chittajallu et al., 2013; Figure 1). Their main excitatory input comes from local PCs to which they send inhibitory feedback (Lacaille et al., 1987), as well as from cholinergic afferents from the septum and diagonal band of Broca (LovettBarron et al., 2012; Sun et al., 2014). They receive inhibition from local inhibitory neurons, mostly vasoactive intestinal peptide (VIP) expressing interneurons, and inhibitory afferents from septal regions (Tyan et al., 2014) and the nucleus incertus (Szonyi et al., 2019).

The main targets of OLM cell axons are the distal dendrites and spines of PCs (Maccaferri et al., 2000). They also target dendrites of other interneurons, such as bistratified cells, basket cells, and interneurons located in stratum radiatum (Schaffer collateral associated cells, perforant path associated cells, and neurogliaform cells; Katona et al., 1999; Elfant et al., 2008; Figure 2). Consequently, CA1 OLM cells provide differential control of PC excitatory afferents: (1) OLM cell activation directly inhibits the distal excitatory inputs of the temporoammonic pathway (TAP); (2) they also inhibit other interneurons, which themselves inhibit the proximal dendrites of CA1 PCs in stratum radiatum, providing indirect disinhibition of the excitatory inputs from the Schaffer collateral pathway (SC). Hence, OLM cells differentially modulate the excitatory synaptic inputs coming from the entorhinal cortex and CA3 onto PCs (Leao et al., 2012; Katona et al., 2014).

Interestingly, OLM cells express a specific set of proteins regulating their excitatory synaptic inputs. They express a high level of the metabotropic glutamate receptor type $1 \alpha$ (mGluR1 $\alpha$; Ferraguti et al., 2004) which localize perisynaptically at their dendritic synapses (Luján et al., 1996). They also express the postsynaptic adhesion molecule, extracellular leucine-rich repeat fibronectin containing 1 (Elfn1) protein, that interacts with the presynaptic receptor mGluR7, expressed specifically at afferent excitatory synapses of OLM cell 
TABLE 1 | Effects of somatostatin (SOM) on hippocampal pyramidal cell activity.

\begin{tabular}{|c|c|c|c|}
\hline Reference & Model & Experiment & Results \\
\hline Hou and Yu (2013) & $\begin{array}{l}\text { Rat hippocampal } \\
\text { neuronal-glial culture }\end{array}$ & 1 day SOM application $1 \mu \mathrm{M}$. & $\begin{array}{l}\searrow \text { Spine density (excitatory) and density of pre-post } \\
\text { synaptic markers. No effect on inhibitory synapses. }\end{array}$ \\
\hline Kluge et al. (2008) & Mouse acute slices & $\begin{array}{l}\text { SOM-KO mice or cysteamine } \\
\text { application. }\end{array}$ & $\begin{array}{l}\text { SOM KO show normal basal synaptic transmission and } \searrow \\
\text { LTP in CA1; same results with cysteamine. }\end{array}$ \\
\hline $\begin{array}{l}\text { Tallent and Siggins } \\
\text { (1997) }\end{array}$ & Rat, acute slices & 1 uM SOM superfusion. & $\begin{array}{l}\text { SOM persistently } \searrow \text { NMDA and AMPA currents in a time } \\
\text { and dose-dependent manner. It has no effect on isolated } \\
\text { GABAergic currents elicited by pyramidal layer stimulation. }\end{array}$ \\
\hline $\begin{array}{l}\text { Scharfman and } \\
\text { Schwartzkroin (1989) }\end{array}$ & Rabbit, acute slices & $\begin{array}{l}\text { Pressure application of SOM on } \\
\text { distinct CA1 pyramidal cell } \\
\text { compartment. }\end{array}$ & $\begin{array}{l}\text { Soma application of SOM depolarizes CA1-PCs and } \\
\text { persistently } \searrow \text { or blocks IPSPs evoked by oriens electrical } \\
\text { stimulation. }\end{array}$ \\
\hline $\begin{array}{l}\text { Scharfman and } \\
\text { Schwartzkroin (1988) }\end{array}$ & Rabbit, acute slices & $\begin{array}{l}\text { Pressure application of SOM on } \\
\text { distinct CA1 pyramidal cell } \\
\text { compartment. }\end{array}$ & $\begin{array}{l}\text { SOM application on pyramidal cell soma elicits } \\
\text { depolarization often accompanied by action potentials. On } \\
\text { dendrites, it produces depolarization or hyperpolarization. } \\
\text { Applied in larger quantities further from the cell it } \\
\text { hyperpolarizes CA1-PCs. Potentiation with } \nearrow \text { spontaneous } \\
\text { activity and evoked responses due to postsynaptic effects. }\end{array}$ \\
\hline Delfs and Dichter (1983) & $\begin{array}{l}\text { Rat cortical neurons in } \\
\text { culture }\end{array}$ & $\begin{array}{l}100 \mathrm{pM} \text { to } 100 \mu \mathrm{M} \text { SOM } \\
\text { application just over the studied } \\
\text { neuron. }\end{array}$ & $\begin{array}{l}\text { Concentration/response curve inverted } U \text { - shaped from } \\
100 \mathrm{pM} \text { to } 1 \mu \mathrm{M} .30-50 \% \text { of the neurons respond } \nearrow \text { with } \\
\text { EPSPs and IPSPS amplitude, and } \nearrow \text { spontaneous action } \\
\text { potentials frequency. }\end{array}$ \\
\hline $\begin{array}{l}\text { Pittman and Siggins } \\
\text { (1981) }\end{array}$ & Rat, acute slices & $\begin{array}{l}\text { Application of } 0.12 \mu \mathrm{M} \text { to } 1.2 \mu \mathrm{M} \\
\text { SOM superfusion on the slice. }\end{array}$ & $\begin{array}{l}\text { Hyperpolarization of PCs and } \searrow \text { evoked and spontaneous } \\
\text { activity. Slight \IPSPs amplitude. Slight } \nearrow \text { EPSPs amplitude } \\
\text { evoked by radiatum stimulation. }\end{array}$ \\
\hline Olpe et al. (1980) & Rat, in vivo, anesthetized & $\begin{array}{l}\text { Hippocampal } 60 \text { s micro-injection } \\
\text { of SOM. }\end{array}$ & $\begin{array}{l}\text { Number of neurons responding with excitation, following } \\
\text { SOM concentration. No alteration of GABA release. }\end{array}$ \\
\hline
\end{tabular}

$\nearrow=$ increase; $\searrow=$ decrease.

(Shigemoto et al., 1996; Sylwestrak and Ghosh, 2012). The Elfn1-mGluR7 interaction facilitates excitatory transmission at these synapses and maximizes excitation in the theta frequency range (4-10 Hz; Sylwestrak and Ghosh, 2012).

The hippocampus displays characteristic oscillatory activities, theta and, gamma oscillations as well as sharp-wave ripples, during exploration and rapid eye movement (REM) sleep (Vanderwolf, 1969; O'Keefe and Nadel, 1978; Buzsaki et al., 1992; Buzsáki, 2002). Thus, the relation of interneuron firing to hippocampal oscillations provides useful functional information (Somogyi et al., 2014). OLM interneurons fire during theta activity at the trough of theta oscillations (Klausberger et al., 2003; Varga et al., 2012; Katona et al., 2014; Somogyi et al., 2014). However, their firing is not coupled to gamma oscillations (Tukker et al., 2007). Also, OLM cell firing is decreased during slow-wave sleep and mostly inhibited during sharp-wave ripples (Klausberger et al., 2003; Varga et al., 2012; Katona et al., 2014). The precise timing of synchronized spikes is crucial for the integration of information because excitatory synapses from CA1 PCs onto SOM interneurons display facilitation on repetitive activation (Ali and Thomson, 1998).

The membrane potential of OLM cells shows intrinsic theta frequency resonance with frequency preferences in theta and low theta ranges (1-5 Hz; Pike et al., 2000). OLM cells display a substantial spike frequency adaptation during sustained discharges (Lacaille and Williams, 1990; Tricoire et al., 2011).
These properties constrain OLM cells to delayed low frequency sustained activity (Pouille and Scanziani, 2004). Thus, the facilitation of synaptic activation of SOM interneurons results in gradual recruitment of sustained inhibition of CA1 PCs (Pouille and Scanziani, 2004).

\section{Bistratified Cells (BiC)}

BiCs express the peptide SOM as well as the other interneuronspecific marker, parvalbumin (PV; Pelkey et al., 2017). Their somas are located in or around the CA1 pyramidal cell layer (BiCs; Figure 1). Their vertical aspinous dendrites arborize in stratum oriens and radiatum (Figure 2; Maccaferri et al., 2000). They receive both feedforward excitation from SC of CA3 PCs and feedback excitation from CA1 PCs (Klausberger et al., 2004). These two major inputs show different short-term dynamics. Repeated stimulation of SC inputs to BiCs show marked and sustained facilitation, whereas similar stimulation of CA1 PCs inputs to BiCs display only an initial transient facilitation (Wierenga and Wadman, 2003; Pouille and Scanziani, 2004). BiCs receive inhibitory synaptic inputs from OLM cells (Leao et al., 2012) and from septal GABAergic neurons (Unal et al., 2018). The designation of $\mathrm{BiC}$ comes from the two-layered distribution of their axonal arborizations in the stratum oriens and stratum radiatum (Figure 2). Accordingly, BiCs strongly inhibit the basal and proximal apical dendrites of CA1 PCs, as 
TABLE 2 | Effects of somatostatin (SOM) on hippocampus-dependent behavior.

\begin{tabular}{|c|c|c|c|}
\hline Reference & Model & Experiment & Results \\
\hline $\begin{array}{l}\text { Gastambide et al. } \\
\text { (2008) }\end{array}$ & Mouse & $\begin{array}{l}\text { Intra-hippocampal injection of SOM or SSTR } \\
\text { agonist at different concentrations before spatial } \\
\text { and cued versions of Morris water maze and } \\
\text { bar pressing conditioning. }\end{array}$ & $\begin{array}{l}\mathrm{SOM} \text { and } \mathrm{SST}_{4} \mathrm{R} \text { agonist injection } \searrow \text { spatial memory } \\
\text { dose-dependently. } \mathrm{SST}_{1-3} \mathrm{R} \text { agonist does not affect these } \\
\text { behavioral tasks. } \mathrm{SST}_{4} \mathrm{R} \text { agonist } \searrow \text { cued memory but } \nearrow \text { bar } \\
\text { pressing retention. }\end{array}$ \\
\hline Kluge et al. (2008) & Mouse & $\begin{array}{l}\text { SOM KO mice or cysteamine injection in wild } \\
\text { type mice. Contextual fear conditioning and } \\
\text { cued fear conditioning. }\end{array}$ & $\begin{array}{l}\text { SOM KO \contextual fear but not cued fear memory. } \\
\text { Pre-conditioning cysteamine injection in wild type mice has } \\
\text { the same effect, but post-conditioning injection induces } \\
\text { unspecific increase of fear response. }\end{array}$ \\
\hline Lamirault et al. (2001) & Mouse & $\begin{array}{l}\text { Intra-hippocampal injection of SOM or } \\
\text { cysteamine prior spatial discrimination } \\
\text { eight-arm radial maze task acquisition or test. }\end{array}$ & $\begin{array}{l}\text { SOM injection prior acquisition }(0.2 \mu \mathrm{g} / 0.2 \mu \mathrm{l} / \mathrm{hippocampus}) \\
\nearrow \text { acquisition speed but } \searrow \text { performances during the test. } \\
\text { Injection before the test does not affect memory. }\end{array}$ \\
\hline Guillou et al. (1993) & Mouse & $\begin{array}{l}\text { Intra hippocampal injection of SOM or } \\
\text { cysteamine prior to spatial discrimination } \\
\text { eight-arm radial maze task. }\end{array}$ & $\begin{array}{l}\text { SOM injection }(0.2 \mu \mathrm{g} / 0.2 \mu \mathrm{l} / \text { hippocampus) } \nearrow \text { acquisition } \\
\text { speed, but impairs the ability to change strategies. } \\
\text { Cysteamine injection impairs memory. }\end{array}$ \\
\hline Vécsei et al. (1989) & Rat & $\begin{array}{l}\text { Intra-cerebroventricular SOM or SOM } \\
\text { fragments injection in male rats directly after } \\
\text { passive avoidance acquisition. }\end{array}$ & $\begin{array}{l}0.6 \mathrm{nM} \text { SOM } \nearrow \text { avoidance latency and } 6 \mathrm{nM} \searrow \text { it in a } \\
\text { passive avoidance task during the test } 24 \mathrm{~h} \text { after. In open } \\
\text { field task } 6 \mathrm{nM} \text { SOM } \searrow \text { rearing and } 0.6 \mathrm{nM} \text { has no effect. } \\
\text { Injections above } 12 \mathrm{nM} \text { are lethal. }\end{array}$ \\
\hline $\begin{array}{l}\text { Vécsei and Widerlöv } \\
\text { (1988) }\end{array}$ & Rat & $\begin{array}{l}\text { Intra-cerebroventricular SOM injection in male } \\
\text { rats } 30 \text { min before passive avoidance, or active } \\
\text { avoidance acquisition. }\end{array}$ & $\begin{array}{l}\text { In passive avoidance: } 1 \mu \mathrm{g} \text { of SOM } \nearrow \text { avoidance latency at } \\
24 \mathrm{~h} \text { but not } 48 \mathrm{~h} \text { after acquisition. } 10 \mu \mathrm{g} \searrow \text { avoidance } \\
\text { latency } 24 \mathrm{~h} \text { after acquisition. In active avoidance: } 1 \mu \mathrm{g} \\
\text { SOM } \nearrow \text { learning curve. }\end{array}$ \\
\hline Vécsei et al. (1984) & Rat & $\begin{array}{l}\text { Intra-cerebroventricular SOM or subcutaneous } \\
\text { cysteamine injection in male rats directly after } \\
\text { active avoidance and T-maze acquisition. }\end{array}$ & $\begin{array}{l}\text { SOM } \searrow \text { extinction of active avoidance but has no effect on } \\
\text { T-maze. Cysteamine } \nearrow \text { extinction in both behavioral tasks. } \\
\text { SOM } \nearrow \text { locomotion in open field } 10 \text { min after injection. } \\
\text { Cysteamine } \searrow \text { locomotion, rearing, and grooming. }\end{array}$ \\
\hline
\end{tabular}

$\nearrow=$ increase; $\searrow$ = decrease.

well as other interneurons (Halasy et al., 1996; Maccaferri et al., 2000).

The action potentials and subsequent after-hyperpolarization of BiCs are fast, enabling these cells to withstand high frequency stimulation with high temporal reliability (Buhl et al., 1996; Pouille and Scanziani, 2004). In relation to hippocampal oscillatory activity, BiCs fire during theta activity in the trough of theta oscillation (Klausberger et al., 2004). In contrast to OLM cells, BiCs show strong modulation of activity during gamma oscillations and fire during the ascending phase of oscillations (Tukker et al., 2007) In addition, BiCs demonstrate high activity during sharp-wave ripples (Katona et al., 2014). BiCs fast-spiking features and the dynamics of their excitatory and inhibitory inputs influence the way they provide recurrent inhibition of PCs. At the beginning of sustained activation of CA1 PC inputs, BiCs respond with reliable time-locked excitation that shows transient facilitation, resulting in onset-transient inhibition of CA1 PCs proximal dendrites (Wierenga and Wadman, 2003; Pouille and Scanziani, 2004). In contrast, OLM cell firing shows a gradual recruitment during sustained activation of CA1 PC inputs, thereby providing a late-persistent type of inhibition (Pouille and Scanziani, 2004). Thus, BiCs and OLM cells provide recurrent inhibition with distinct dynamics, targeting proximal vs. distal CA1 PC dendrites respectively (Wierenga and Wadman, 2003; Pouille and Scanziani, 2004; Muller and Remy, 2014).

\section{Hilar Perforant Path (HIPP) Cells}

HIPP cells of the dentate gyrus (DG) have their soma and dendritic arborizations in the hilus (Sik et al., 1997; Yuan et al., 2017). Their axonal projections heavily ramify in the outer two-thirds of the molecular layer (Figure 1; Han et al., 1993; Yuan et al., 2017). Although the majority of HIPP axon processes terminate in the DG, some branches traverse the hippocampal fissure and project to the CA1 stratum lacunosummoleculare (Han et al., 1993; Houser, 2007). HIPP cells are mainly excited by granule cell (GC) axons and provide feedback inhibition to distal dendrites of GCs, thereby showing functional similarities with OLM cells (Hosp et al., 2014). HIPPs form functional synapses with GCs, but also with PV interneurons and other HIPP cells. They also rarely connect to CCK hilar commissural associational path (HICAP) interneurons (Savanthrapadian et al., 2014). HIPP provides weak and slow dendritic inhibition (Yuan et al., 2017). However, their inhibition of PV cells is sufficient to regulate their action potential generation and spike timing precision, and hence, control information flow within the DG circuitry (Savanthrapadian et al., 2014).

\section{Radiatum (R) Cells}

Other subtypes of SOM cells, that are sparse in number, are found in stratum radiatum (Figure 1; Oliva et al., 2000; Tricoire et al., 2011). One type of SOM interneuron was 


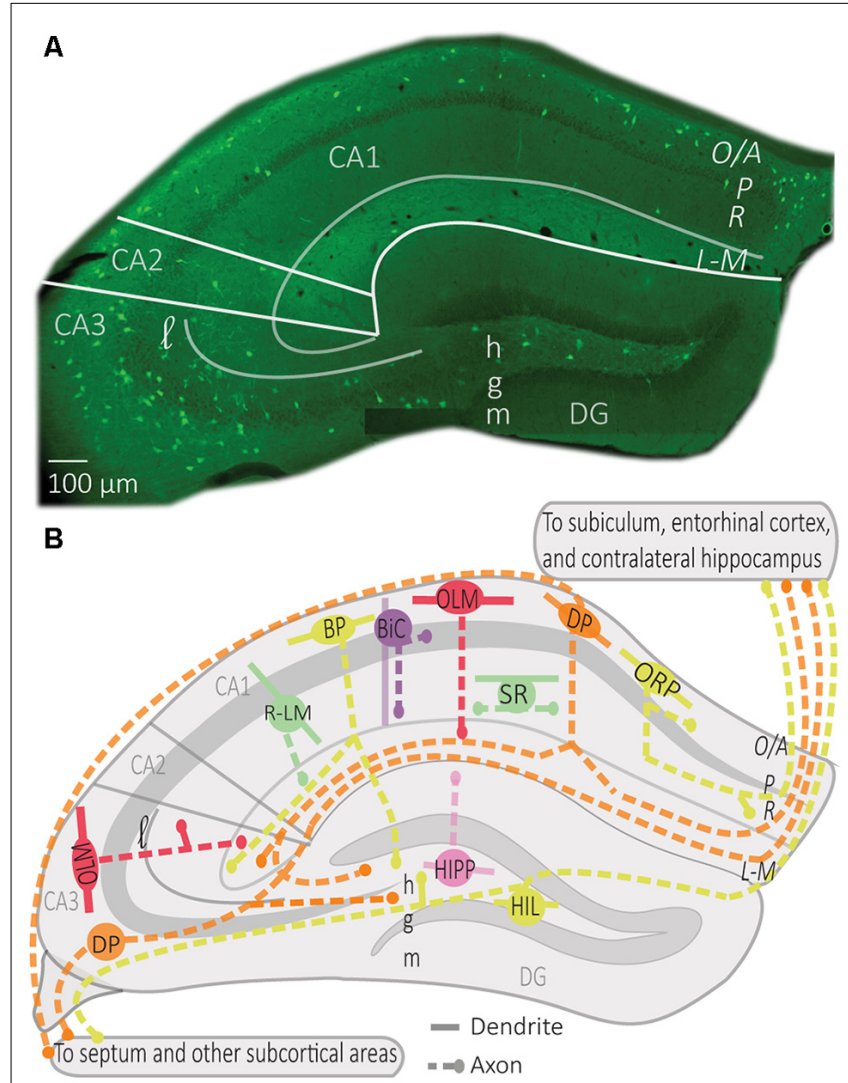

FIGURE 1 | Distribution of somatostatin (SOM) interneurons in hippocampus. (A) Representative montage of fluorescence images showing the soma location of SOM interneurons expressing the enhanced yellow fluorescent protein in the dorsal hippocampus of Sstires-Cre $;$ Rosa26 $6^{\text {Isl-EYFP }}$ mice (Vasuta et al., 2015; Artinian et al., 2019), with indicated anatomical landmarks. (B) Simplified diagram illustrating the characteristic position of soma, dendrites, and axons of the different types of SOM interneurons in hippocampus. Abbreviations for hippocampus: CA1-3, cornu ammonis 1-3; $\mathrm{DG}$, dentate gyrus; O/A, oriens/alveus; P, pyramidale; $\mathrm{R}$, radiatum; L-M, lacunosum-moleculare; I, lucidum; h, hilus; g, granule cell layer; m, moleculare. Abbreviations for SOM interneuron types: OLM, oriens/lacunosum-moleculare cell; ORP, oriens-retrohippocampal projecting cell; DP, double projecting cell; BP, back-projecting cell; BiC, bistratified cell; R-LM, radiatum/lacunosum-moleculare cell; SR, stratum radiatum cell; HIPP, hilar perforant path cell; HIL, hilar cell.

identified in a transgenic mice line (GFP-expressing Inhibitory Neurons, GIN mice; Oliva et al., 2000). These CA1 SOM interneurons have a cell body in stratum radiatum and dendrites that span stratum oriens and stratum radiatum. Their axonal projections ramify in stratum lacunosum-moleculare and these cells were designated radiatum-lacunosum moleculare (RLM cells; Figure 1; Oliva et al., 2000). RLM cells show similar firing properties to OLM cells (Oliva et al., 2000). Hence, RLM cells may provide feedforward inhibition of entorhinal cortex input of PCs (Oliva et al., 2000). Another type of SOM cell was identified with the soma, dendrites and axonal projections restricted to stratum radiatum (SR cells; Figure 1; Oliva et al., 2000; Tricoire et al., 2011). These SOM cells have similar firing properties to OLM cells and may provide feedforward inhibition of Schaffer collateral input to CA1 pyramidal cells (Oliva et al., 2000; Tricoire et al., 2011).

\section{Projection Cells}

Distinct SOM interneurons, in addition to providing local inhibition, have projections to other hippocampal and subcortical areas, where they target many cell types including PCs and GABA interneurons (Gulyas et al., 2003; Katona et al., 2017; Eyre and Bartos, 2019). In CA1, these SOM projecting cells have their soma and dendrites in stratum oriens, as well as local axonal arborizations in stratum oriens and stratum radiatum. Distinct CA1 SOM projection cells are distinguished by their axonal projection targets (Figure 1). Back-projecting (BP) cells have axonal projections to CA3 and DG (Goldin et al., 2007; Katona et al., 2017). Oriens-retrohippocampal projecting (ORP) cells project to the subiculum (Jinno et al., 2007; Melzer et al., 2012). Doubleprojecting (DP) cells have axons projecting to the septum, as well as to CA3 and DG (Gulyas et al., 2003; Katona et al., 2017; Eyre and Bartos, 2019), subiculum (Goldin et al., 2007; Jinno et al., 2007; Melzer et al., 2012) or the medial entorhinal cortex and contralateral hippocampus (Goldin et al., 2007; Jinno et al., 2007; Melzer et al., 2012; Eyre and Bartos, 2019). Much less is known about the physiological properties of these cell types, although in vivo recordings indicate that most projection cells discharge during theta activity in the descending slope or at the trough of theta cycles during movement (Jinno et al., 2007; Katona et al., 2017). Some projection cells fire preferentially on the ascending phase of gamma oscillations (Jinno et al., 2007). Most of them also increase their firing during sharp-wave ripples (Jinno et al., 2007; Katona et al., 2017). Thus, SOM projection cells tend to fire similarly to $\mathrm{BiC}$ cells during hippocampal oscillations.

In CA3, DP cells were described with soma in stratum oriens, pyramidale, and lucidum (Gulyas et al., 2003; Jinno et al., 2007; Figure 1). CA3 DP cells have dendrites in stratum oriens and radiatum, as well as local axons in stratum oriens, pyramidale and radiatum (Jinno et al., 2007). CA3 DP cells have axonal longrange projections that target the septum, as well as CA1 and subiculum (Jinno et al., 2007) and ventral hippocampal areas (Gulyas et al., 2003). CA3 DP cell axonal long-range projections make synaptic contacts with $\mathrm{PCs}$ and GABA interneurons (Gulyas et al., 2003; Jinno et al., 2007).

In DG, another type of SOM cell is the hilar cell (HIL, Figure 1). HIL cells have a cell body, dendrites, and local axonal projections in the hilus (Yuan et al., 2017). Their activity is driven by excitatory inputs from GCs and DG mossy cells (Larimer and Strowbridge, 2008; Yuan et al., 2017). HIL cells provide perisomatic inhibition of hilar GABAergic cells and mossy cells and send long-range axonal projections to the medial septum (Gulyas et al., 2003; Larimer and Strowbridge, 2008; Yuan et al., 2017) and contralateral DG (Gulyas et al., 2003; Goldin et al., 2007; Jinno et al., 2007; Eyre and Bartos, 2019). By exerting a powerful inhibition onto local GABAergic and mossy cells, as well as septal neurons, HIL cells can coordinate activities in these 


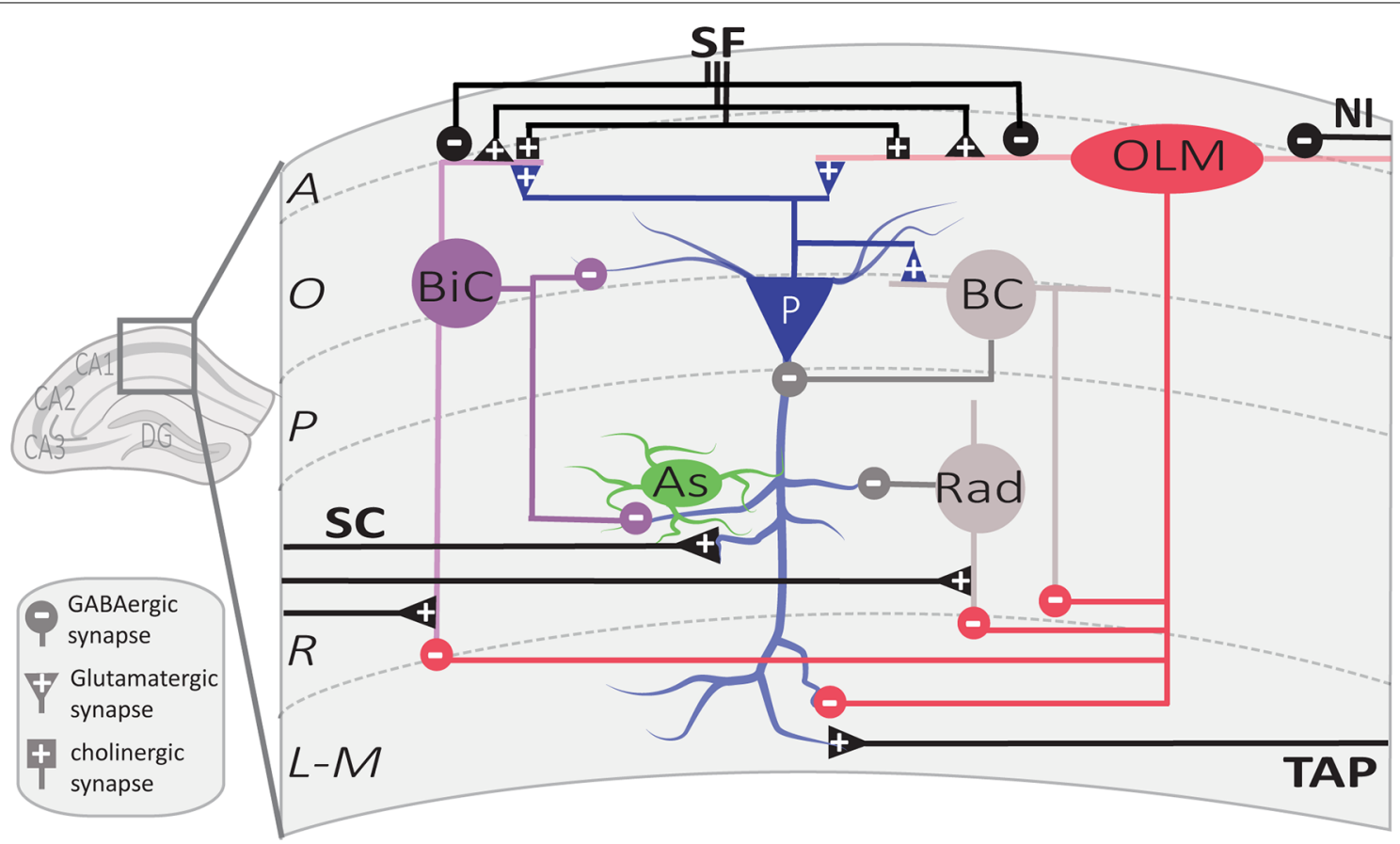

FIGURE 2 | Local circuit of CA1 SOM interneurons. Simplified diagram illustrating the local synaptic circuits of OLM cells and BiCs with other cell types in dorsal CA1 hippocampus. Abbreviations for CA1 layers: A, alveus; O, oriens; P, pyramidale; R, radiatum; L-M, lacunosum-moleculare. Abbreviations for CA1 afferent inputs: SF, septal fibers; NI, nucleus incertus fibers; SC, Schaffer collateral pathway from CA3 pyramidal cells; TAP, temporo-ammonic pathway from entorhinal cortex. Abbreviations for SOM cell types: (red) OLM, oriens/lacunosum-moleculare cell; (violet) BiC, bistratified cell. Abbreviations for other cell types: (blue) P, pyramidal cell; (gray) BC, basket cell; (green) As, astrocyte; (gray) Rad, unidentified stratum radiatum interneurons targeted by OLM cells.

areas as a function of GC and mossy cell activation (Larimer and Strowbridge, 2008; Yuan et al., 2017).

\section{SOM INTERNEURONS LONG-TERM SYNAPTIC PLASTICITY}

In the central nervous system, two widely studied forms of long-term synaptic plasticity are long-term potentiation (LTP), a long-lasting strengthening of synaptic efficacy, and longterm depression (LTD), a long-lasting weakening of synaptic efficacy (Malenka and Bear, 2004). These forms of synaptic plasticity at hippocampal excitatory synapses are linked to memory storage (Morris, 2003). In vitro, several protocols of electrical stimulations, or repetitive pairing of pre- and post-synaptic firing, induce long-term changes of synaptic transmission (Malenka and Bear, 2004; Caporale and Dan, 2008). With electrical stimulation, LTP is generally associated with high frequency afferent stimulation, and LTD with low frequency stimulation. With pre- and post-synaptic pairing, a presynaptic spike preceding the postsynaptic spike within a narrow time window induces LTP, whereas the reverse produces LTD (Feldman, 2012). Although it has been known for some time that blocking GABAergic transmission facilitates the induction of LTP at excitatory synapses (Wigstrom and Gustafsson, 1983) and that afferents of inhibitory interneurons display long-term potentiation (Buzsaki and Eidelberg, 1982), synaptic plasticity at excitatory synapses onto interneurons has recently attracted more attention (Kullmann and Lamsa, 2007; Pelletier and Lacaille, 2008). It is becoming increasingly apparent that hippocampal inhibitory neurons, including SOM interneurons, have highly dynamic activity and express long-lasting changes at their excitatory input synapses and inhibitory output synapses (Maccaferri and McBain, 1996; Perez et al., 2001; Lamsa et al., 2005; Chevaleyre et al., 2006; Kullmann and Lamsa, 2007, 2011; Pelletier and Lacaille, 2008; Vasuta et al., 2015; Udakis et al., 2020). In this section, we will focus on long-term plasticity at excitatory synapses onto hippocampal SOM interneurons (Perez et al., 2001) and later examine its role in hippocampus-dependent memory.

\section{Excitatory Synapses Onto CA1 SOM Interneurons}

Plasticity of excitatory synapses onto SOM interneurons has been characterized the most in CA1 OLM cells (Lacaille et al., 1987; Maccaferri and McBain, 1996; Perez et al., 2001; Lamsa et al., 2007). Excitatory synapses made by CA1 PC axons that feedback on CA1 SOM interneurons (notably OLM cells) are composed of $\mathrm{Ca}^{2+}$ permeable AMPA receptors (CP-AMPARs). These synapses show inward rectification of their current-voltage (I-V) relationship, display short-term facilitation with repeated stimulation, and are inhibited by mGluR2/3 (Croce et al., 2010). In contrast, excitatory synapses made by axons of CA3 PCs 
that feed-forward onto CA1 SOM interneurons (OLM cells) are composed of $\mathrm{Ca}^{2+}$ impermeable AMPARs (CI-AMPARs), and these synapses show linear I-V relationships, display short-term depression with repeated stimulation, and are mGluR2/3insensitive (Croce et al., 2010). These input-specific properties of excitatory synapses differentially control the SOM interneuron output firing, resulting in gradual sustained recruitment of evoked firing with repetitive feedback input activation, and transient evoked firing with repetitive feedforward input activation of SOM cells (Croce et al., 2010). It is interesting to note that input-specific rules of excitatory synapses also occur for other types of interneurons in CA3 stratum lucidum (SL) but with the opposite organization (Toth and McBain, 1998). Thus, excitatory synapses onto single SOM cells originate from multiple sources and display afferent-specific mechanisms. In addition, these afferent-specific mechanisms differ from those in other types of interneurons.

\section{Long-Term Potentiation at Excitatory Synapses Onto SOM Interneurons}

The synapse between CA1 PC axons and SOM interneurons, notably BiC and OLM cells, express a Hebbian form of LTP that requires the coincident activity of both pre- and postsynaptic neurons for induction (Perez et al., 2001; Lapointe et al., 2004; Vasuta et al., 2015). Multiple lines of evidence indicate that this SOM interneuron LTP is not due to passive propagation of di-synaptic LTP at Schaffer collateral synapses on CA1 pyramidal cells (SC-CA1 synapses; McBain et al., 1999). First, SOM interneuron LTP is insensitive to the NMDA receptor blocker AP-5 (Perez et al., 2001), unlike LTP at SC-CA1 PC synapses (Morris et al., 1986). Second, LTP is induced directly at putative single fiber synapses onto SOM interneurons by using minimal stimulation (Perez et al., 2001; Lapointe et al., 2004; Vasuta et al., 2015). Finally, interfering with $\mathrm{Ca}^{2+}$ influx in the postsynaptic SOM interneuron prevents LTP induction (Lapointe et al., 2004).

This LTP is considered Hebbian since it is induced by presynaptic theta-burst stimulation (TBS) paired with postsynaptic depolarization (Figure 3), but not by presynaptic stimulation alone nor postsynaptic depolarization alone (Perez et al., 2001). Hebbian LTP is expressed as a decrease in failure rates of EPSCs and an increase in the potency of EPSCs (amplitude of EPSCs excluding failures; Perez et al., 2001; Lapointe et al., 2004). It is also accompanied by a change in paired-pulse facilitation and the coefficient of variation of EPSCs, parameters associated with presynaptic changes (Lapointe et al., 2004). Thus, Hebbian LTP may be expressed by both pre- and post-synaptic mechanisms.

Hebbian LTP in SOM interneurons shows afferent input specificity. Pairing presynaptic TBS with postsynaptic depolarization elicits LTP at synapses between CA1 PCs and SOM interneurons, but not at the synapses between CA3 PCs and SOM interneurons (Croce et al., 2010). Also, it displays cell-type specificity. Pairing presynaptic TBS with postsynaptic depolarization evoked LTP in SOM interneurons (BiC and OLM cells; Perez et al., 2001; Lapointe et al., 2004; Vasuta et al., 2015) but not in PV interneurons (Vasuta et al., 2015) nor in

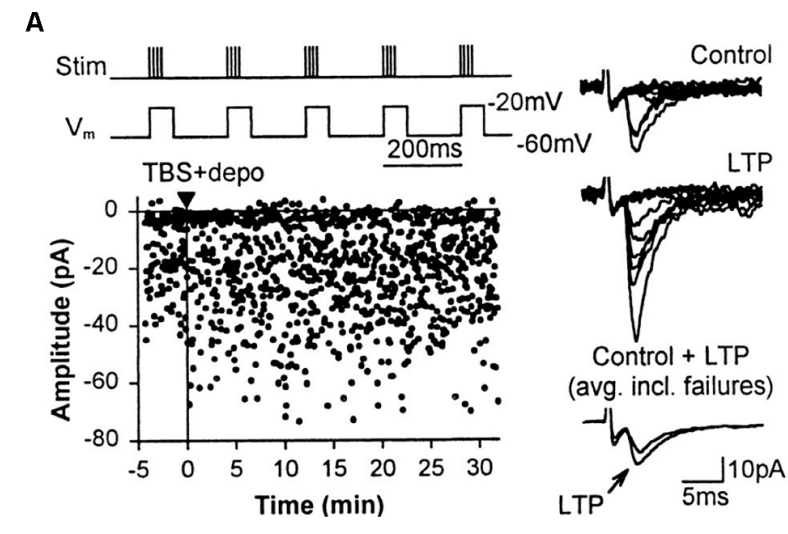

B CA1 PC Presynaptic terminal Glutamatergic or cholinergic terminal

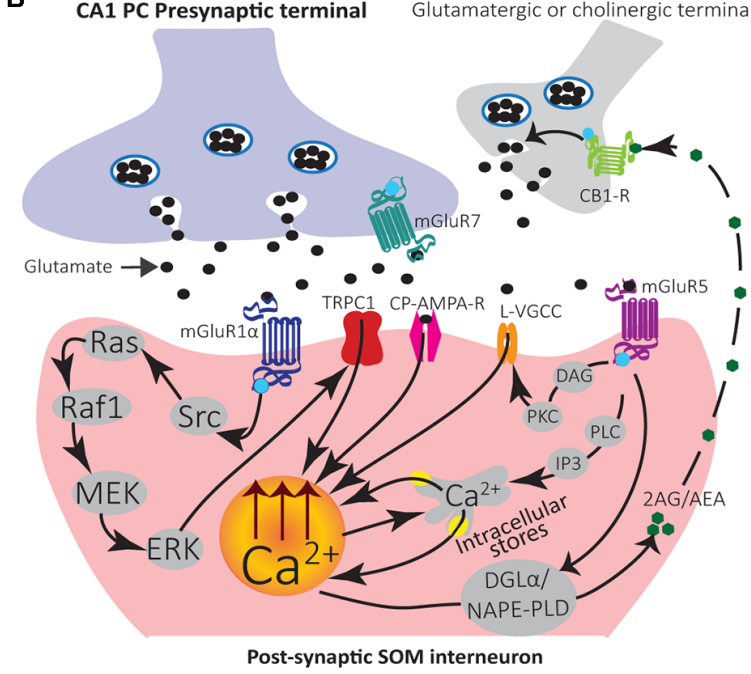

FIGURE 3 | Mechanisms of induction and modulation of Hebbian LTP in SOM interneurons. (A) Graph of EPSC amplitude from a representative cell showing LTP after TBS paired with depolarization (TBS + depo; protocol shown above and delivered at time indicated by black triangle and vertical line). Examples of control and potentiated EPSCs (10 consecutive responses) at $30 \mathrm{~min}$ after induction (Right). Superimposed average EPSCs (bottom traces; $n=64$ responses each, failures included) from control and $30 \mathrm{~min}$ after induction also show LTP. Adapted from Perez et al. (2001). (B) Diagram of LTP induction mechanisms leading to postsynaptic $\mathrm{Ca}^{2+}$ elevation in SOM interneurons. Stimulation of the presynaptic terminal releases glutamate that activates postsynaptic CP-AMPAR and mGluR1 $\alpha$. Activation of mGluR1 $\alpha$ stimulates the Src signaling cascade leading to ERK activation. ERK leads to postsynaptic $\mathrm{Ca}^{2+}$ rise via activation of non-selective cationic channels TRPC1 and $\mathrm{Ca}^{2+}$ entry, as well as mobilization of $\mathrm{Ca}^{2+}$ from intracellular stores. A retrograde signaling mechanism may involve eCBs. Synaptic activation of mGluR1/5 stimulates synthesizing enzymes DGL $\alpha$ and/or NAPE-PLD to produce the eCBs 2-AG and/or AEA. 2-AG/AEA act retrogradely to activate $\mathrm{CB} 1 \mathrm{Rs}$ on glutamatergic or cholinergic terminals and potentiate transmission. A potential mechanism of LTP modulation may involve activation of mGluR5 that produces postsynaptic $\mathrm{Ca}^{2+}$ rises via two pathways. First, mGluR5 activates the PLC/IP3 pathway which leads to $\mathrm{Ca}^{2+}$ release from internal stores. Second, mGluR5 activates DAG-PKC pathway to potentiate L-type VGCC function and may regulate LTP induction.

unidentified interneurons in stratum radiatum (Perez et al., 2001).

Induction of Hebbian LTP in SOM interneurons involves a very different signaling cascade than LTP in PCs (Figure 3). Most 
notably, Hebbian LTP in SOM interneurons does not involve NMDA receptors (Perez et al., 2001), but requires the activation of mGluR1a receptors, a glutamate metabotropic receptor highly expressed in SOM interneurons (Perez et al., 2001; Kougioumoutzakis et al., 2020). Pharmacologically blocking mGluR $1 \alpha$, or genetically deleting mGluR1 (mGluR1 ${ }^{-} /^{-}$mice), prevents Hebbian LTP induction, indicating a crucial role of mGluR1 $\alpha$ (Perez et al., 2001; Lapointe et al., 2004; Topolnik et al., 2005; Vasuta et al., 2015). During induction of Hebbian LTP, the activation of postsynaptic mGluR $1 \alpha$ stimulates Src and extracellular signal-regulated kinase (ERK) pathways, causing the opening of transient receptor potential (TRP) channels and $\mathrm{Ca}^{2+}$ influx, as well as $\mathrm{Ca}^{2+}$ release from intracellular stores (Topolnik et al., 2006; Figure 3). TRPC1 interaction with mGluR1 $\alpha$ in SOM interneuron dendrites mediates a mGluR $1 \alpha$-dependent slow EPSC in SOM interneurons, supporting the importance of TRP channels in SOM interneurons LTP (Kougioumoutzakis et al., 2020).

Endocannabinoid (eCB) signaling mainly mediates short- and long-term depression of excitatory and inhibitory transmission (Chevaleyre et al., 2006). In addition, synaptic activation of group I mGluRs (mGluR1/5) is a major pathway for the production of eCBs (Chevaleyre et al., 2006). Interestingly in SOM interneurons, eCBs may be involved as a retrograde messenger in LTP (Friend et al., 2019). SOM interneurons express the endocannabinoid-synthesizing enzyme diacylglycerol lipase $\alpha$ (DGL $\alpha$ ) and n-acylphosphatidylethanolamine phospholipase D (NAPE-PLD; Friend et al., 2019). Moreover, inhibition of cannabinoid type 1 receptor (CB1R) prevents LTP in SOM interneurons (Friend et al., 2019). Thus, synaptic activation of mGluR1/5 may lead to the production of eCBs (anandamide, AEA; 2-arachadonyl glycerol, 2-AG) that act retrogradely on presynaptic CB1Rs to potentiate synaptic transmission (Figure 3; Friend et al., 2019).

Activation of mGluR5 in SOM interneurons (OLM cells) also elicits postsynaptic $\mathrm{Ca}^{2+}$ rises from intracellular stores release, independent of Src-ERK activation (Topolnik et al., 2006). Moreover, this type of $\mathrm{Ca}^{2+}$ signaling is not involved directly in Hebbian LTP induction (Topolnik et al., 2006). Pharmacological activation of mGluR5 is sufficient to induce LTP at excitatory synapses onto SOM interneurons (OLM cells), indicating multiple types of LTP linked to mGluRs in SOM interneurons (Le Vasseur et al., 2008). In addition, local mGluR5 activation by agonist application or high frequency synaptic stimulation leads to sustained enhancement of action potential evoked $\mathrm{Ca}^{2+}$ transients in dendrites of SOM interneurons (OLM cells; Topolnik et al., 2009). This augmentation of postsynaptic $\mathrm{Ca}^{2+}$ transients is expressed as a selective potentiation of L-type voltage-gated calcium channels (VGCCs) function and controlled by mGluR5-mediated intracellular $\mathrm{Ca}^{2+}$ release as well as protein kinase C (PKC) activation (Figure 3; Topolnik et al., 2009). This activity-dependent regulation of VGCCs by mGluR5 may serve as a mechanism for positively regulating Hebbian synaptic plasticity of SOM interneurons (Topolnik et al., 2009).

In pyramidal cells, $\mathrm{GABA}_{\mathrm{B}} \mathrm{Rs}$ mediate a slow $\mathrm{K}^{+}{ }^{+}$-mediated inhibitory postsynaptic current (sIPSC; Dutar and Nicoll, 1988;
Degro et al., 2015) and promote excitatory synapses LTP via a presynaptic disinhibition mechanism (Davies et al., 1991; Mott and Lewis, 1991). In SOM interneurons, $\mathrm{GABA}_{\mathrm{B}} \mathrm{Rs}$ are also highly expressed in dendrites. But instead of activating postsynaptic $\mathrm{K}^{+}$currents, $\mathrm{GABA}_{\mathrm{B}}$ Rs inhibit postsynaptic L-type VGCCs in SOM interneurons (Booker et al., 2018). By negatively regulating VGCCs, $\mathrm{GABA}_{\mathrm{B}}$ Rs inhibit Hebbian LTP in SOM interneurons (Booker et al., 2018). Thus, GABA ${ }_{B}$ R-mediated inhibition of L-type VGCCs provides a mechanism for negative regulation of Hebbian synaptic plasticity of SOM interneurons. Interestingly, excitatory and inhibitory synaptic inputs onto SOM interneurons are inhibited presynaptically by $\mathrm{GABA}_{\mathrm{B}} \mathrm{Rs}$, as well as SOM interneuron inhibitory synapses onto PCs (Booker et al., 2020). Thus, $\mathrm{GABA}_{\mathrm{B}} \mathrm{R}$ activation may also functionally uncouple SOM interneurons from the CA1 network (Booker et al., 2020).

\section{Persistent Long-Term Potentiation at Excitatory Synapses Onto SOM Interneurons}

LTP in principal cells is divided into two phases: an early phase (early LTP, E-LTP) that is induced by brief high frequency stimulation, lasts several minutes to hours and depends on post-translational mechanisms; and a late phase (late LTP, L-LTP) that requires repetitive high frequency stimulation, lasts several hours to days and depends on new gene expression and protein synthesis (Kandel, 2001; Abraham et al., 2019). Although the study of late LTP has mainly focused on excitatory synapses onto principal cells (Malenka and Bear, 2004), recent studies revealed that excitatory synapses onto CA1 SOM interneurons can also undergo L-LTP (Ran et al., 2009, 2012; Artinian et al., 2019).

In hippocampal slice culture, repetitive stimulation of mGluR1, by the repeated application of the mGluR1/5 agonist (RS)-3, 5-dihydroxyphenylglycine (DHPG), in the presence of the mGluR5 antagonist 2-methyl-6-(phenylethynyl) pyridine (MPEP), induces a persistent potentiation of excitatory synapses onto SOM interneurons that can last at least $24 \mathrm{~h}$, termed

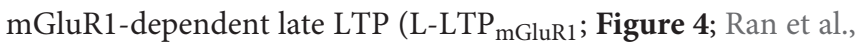

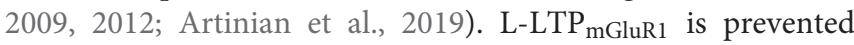
by inhibitors of transcription and translation, indicating that it is dependent on new gene expression and protein synthesis

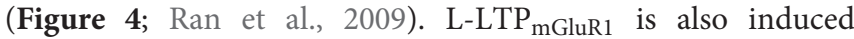
in acute hippocampal slices by repeated mGluR1 stimulation with DHPG, or by repetitive theta-burst stimulation of afferents (Artinian et al., 2019). Interestingly, using ex vivo whole-cell recordings in acute slices $24 \mathrm{~h}$ after contextual fear conditioning, training was found to induce mGluR1mediated, translation-dependent L-LTP at SOM interneuron excitatory synapses, indicating that L-LTP ${ }_{\text {mGluR1 }}$ may be linked to hippocampus-dependent memory (Artinian et al., 2019).

Mechanistically, L-LTP ${ }_{\text {mGluR1 }}$ shares many features of Hebbian LTP. Repetitive stimulation of mGluR1 by DHPG during action potentials blockade with tetrodotoxin prevent

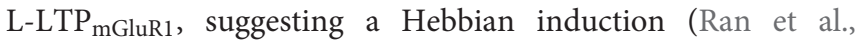




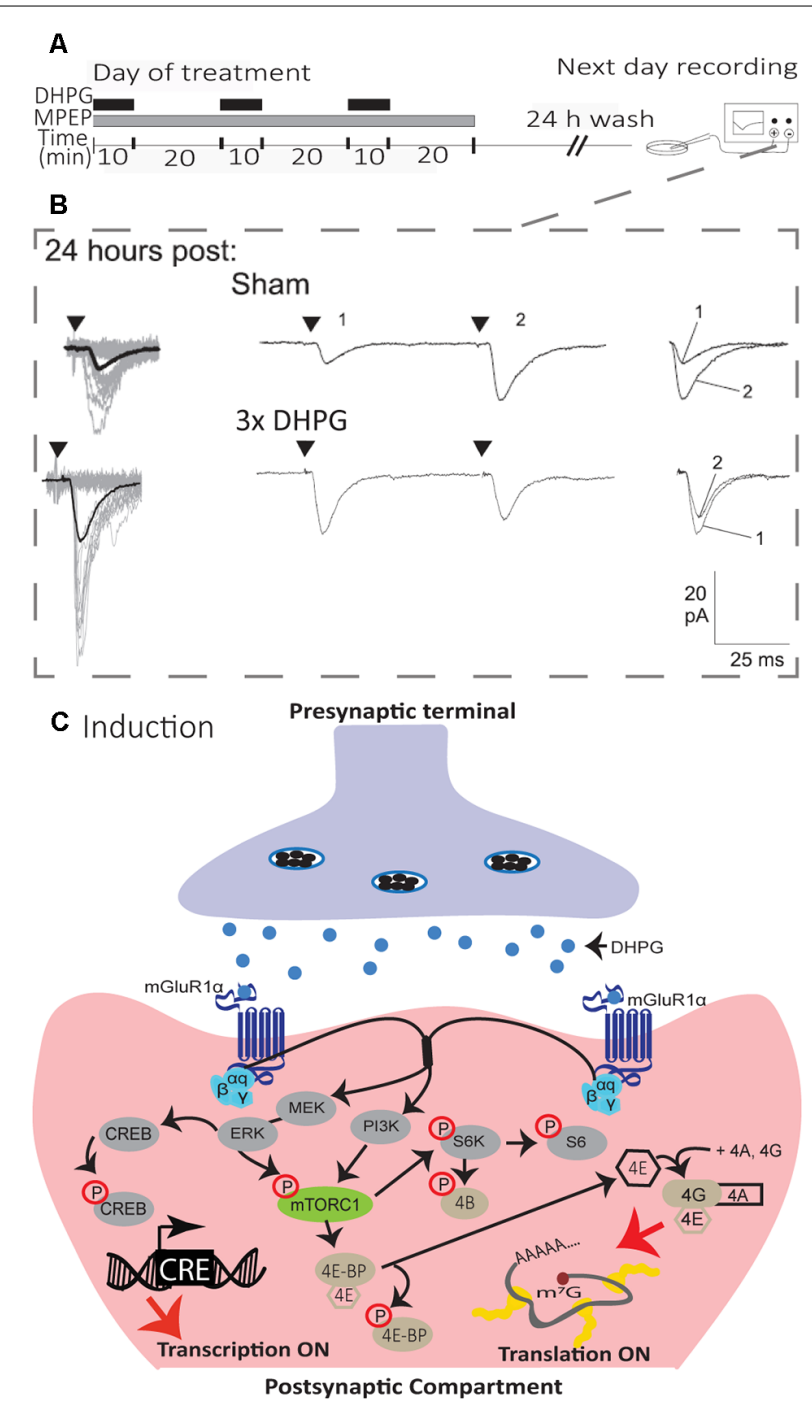

D Expression

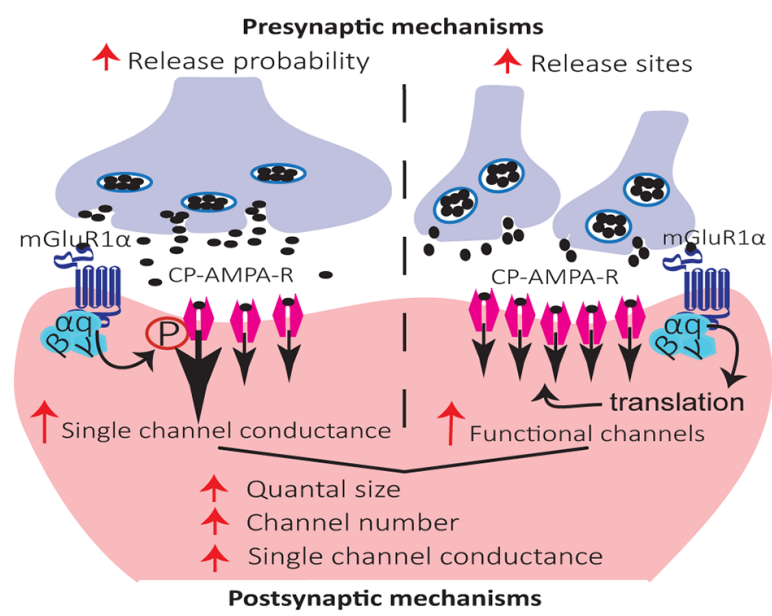

FIGURE 4 | Mechanisms of induction and expression of L-LTP mGluR1 in SOM interneurons. (A) Schematics of induction and recording protocol. Cultured

(Continued)
FIGURE 4 | Continued

hippocampal slices were treated with repetitive $(3 x)$ applications of the mGluR1/5 agonist (DHPG, $5 \mu \mathrm{M}$, black bars) in the presence of the mGluR5 antagonist (MPEP, $25 \mu \mathrm{M}$, gray bar). On the next day, after a $24 \mathrm{~h}$ wash-out, whole cell recordings were obtained from visually identified CA1 SOM interneurons in agonist- or sham-treated slices. (B) Representative EPSCs evoked by minimal stimulation at $24 \mathrm{~h}$ after sham-treatment (top), repetitive ( $3 \times$; bottom) mGluR1 agonist-stimulation, showing larger responses after repetitive treatment. Left, superimposed 20 successive events (EPSCs + failures; gray) with average EPSC (including failures; solid black line) of 100 events. Middle, average of EPSC pairs (100 events) evoked by paired-pulse stimulation (50 ms interstimulus interval), showing loss of paired-pulse facilitation after repetitive treatment. Right, superimposed first and second EPSCs of average pair. Black triangles indicate the time of stimulation. Adapted from Ran et al. (2009). (C) Diagram of L-LTPmGluR1 induction mechanisms. Repeated stimulation of mGluR1 by DHPG engages PI3K and MEK/ERK signaling pathways to phosphorylate mTORC1.

Activation of mTORC1 leads to initiation of elF4E-mediated mRNA translation via to pathways: (1) ribosomal S6 protein kinase (S6K) stimulation of S6 phosphorylation; and (2) phosphorylation of 4E-BPs repressors proteins which release elF4E. Subsequently, elF4E associates with elF4A and elF4G to form the cap-binding complex, elF4F, which initiates translation. Activation of MEK-ERK signaling by repeated mGluR1 stimulation also leads to phosphorylation of CREB to control CRE-dependent gene expression.

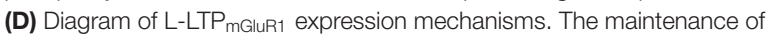

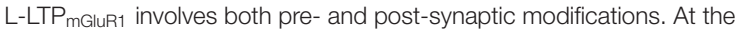
presynaptic level, transmitter release is increased (increase in release probability and/or addition of functional release site). At the postsynaptic level, postsynaptic responsiveness is increased (recruitment of functional receptors and increase in single-channel conductance).

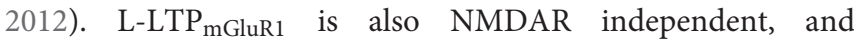

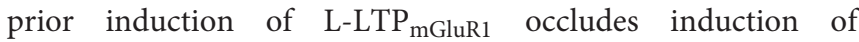
Hebbian LTP, indicating that they share similar mechanisms (Ran et al., 2012).

The mechanisms of induction of L-LTP ${ }_{\text {mGluR1 }}$ (Figure 4) requires activation of $m G l u R 1 \alpha$, as it is prevented by the selective antagonist LY367385 (Ran et al., 2009; Artinian et al., 2019). Activation of mGluR1 $\alpha$ stimulates both phosphoinositide 3-kinase (PI3K) and mitogen-activated protein kinase kinase (MEK)/extracellular signal-regulated kinase (ERK) pathways resulting in mTORC1 phosphorylation. In turn, mTORC1 activates ribosomal protein S6 kinase (S6K) and S6 phosphorylation, as well as phosphorylation of eIF4Ebinding protein (4E-BP), to stimulate eIF4E-dependent

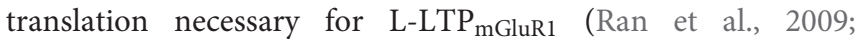
Artinian et al., 2019). In addition activation of mGluR1 $\alpha$ stimulates phosphorylation of cAMP response element-binding protein (CREB) via ERK signaling, to activate CREB-dependent

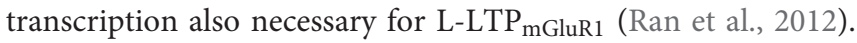
A cell-specific conditional knock-out in SOM interneurons of the Regulatory-Associated Protein of mTOR (Raptor) gene, a necessary component of $\mathrm{mTORC} 1$, reduces mTORC1 activity

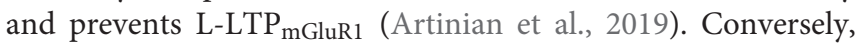
cell-specific conditional heterozygous knock-out in SOM interneurons of the Tuberous Sclerosis Complex 1 (TSC1) gene, a repressor of $\mathrm{mTORC1}$, increases mTORC1 activity in SOM interneurons and facilitates $\mathrm{L}_{-} \mathrm{LTP}_{\mathrm{mGluR} 1}$ by lowering the threshold for induction (Artinian et al., 2019). Knock-out of the $4 \mathrm{E}-\mathrm{BP}$ gene, which removes the repression of eIF4E-dependent 
translation, similarly causes a facilitation of $\mathrm{L}_{\mathrm{LTP}} \mathrm{LTluR}_{\mathrm{m}}$ by lowering the threshold for induction (Ran et al., 2009), further highlighting the critical role of mTORC1-dependent translation in L-LTP $\mathrm{mGluR}_{1}$ (Figure 4).

The mechanisms of expression of synaptic plasticity in central neurons are varied and complex (Citri and Malenka, 2008). In SOM interneurons, $\mathrm{L}-\mathrm{LTP}_{\mathrm{mGluR} 1}$ expression may involve both pre- and postsynaptic mechanisms, not occurring necessarily jointly (Figure 4; Ran et al., 2009, 2012; Artinian et al., 2019). In slice cultures, $\mathrm{L}_{-\mathrm{LTP}} \mathrm{mGluR1}_{1}$ is expressed by an increase in potency of EPSCs evoked by minimal stimulation (Ran et al., 2009; Artinian et al., 2019), and in amplitude of miniature EPSC (mEPSCs; Ran et al., 2009), suggesting postsynaptic mechanisms of expression. L-LTP $\mathrm{mGluR}_{1}$ in slice cultures is accompanied by a reduction in the paired-pulse ratio of EPSCs evoked by minimal stimulation (Ran et al., 2009; Artinian et al., 2019) and by an increase in mEPSC frequency (Ran et al., 2009), suggesting presynaptic mechanisms of expression. Moreover, quantal analysis of EPSCs evoked by minimal stimulation in slice culture indicated an increase in quantal content and quantal size during $\mathrm{L}-\mathrm{LTP}_{\mathrm{mGluR} 1}$, consistent with coordinated pre- and post-synaptic changes (Ran et al., 2012). The increase in quantal content may result from increased release probability or new release sites (Ran et al., 2012). Conforming with the increase in quantal size, peak-scaled nonstationary fluctuation analysis of mEPSCs indicated that an increase in both single-channel conductance and number of functional receptors contribute to the increase in the postsynaptic response during L-LTP $\mathrm{mGluR}_{1}$

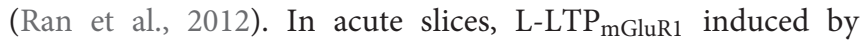
DHPG is expressed by an increase in EPSC potency, but no change in paired-pulse ratio, whereas $\mathrm{L}_{-} \mathrm{LTP}_{\mathrm{mGluR} 1}$ induced by TBS stimulation is expressed by an increase in EPSC potency and a decrease in paired-pulse ratio (Artinian et al., 2019). Similarly, L-LTP ${ }_{\mathrm{mGluR} 1}$ induced by contextual fear conditioning is expressed by an increase in spontaneous EPSC amplitude and frequency, as well as an increase in potency of EPSCs evoked by minimal stimulation but no change in the pairedpulse ratio (Artinian et al., 2019), indicating that pre- and post-synaptic expression mechanisms do not always occur jointly during L-LTP ${ }_{\mathrm{mGluR} 1}$.

\section{Other Types of Synaptic Plasticity in SOM Interneurons}

Interestingly, another form of plasticity called anti-Hebbian LTP is induced at excitatory synapses onto CA1 OLM interneurons by pairing presynaptic stimulation with postsynaptic membrane hyperpolarization (Kullmann and Lamsa, 2007). The anti-Hebbian LTP is NMDAR-independent and dependent on CP-AMPARs. This form of LTP is not specific to SOM interneurons and can be induced in fast-spiking $\mathrm{PV}$ interneurons (axo-axonic cells and basket cells; Kullmann and Lamsa, 2007). The diversity in types of long-term plasticity at SOM interneuron synapses in the hippocampal CA1 region suggests multiple roles in long-lasting regulation of the CA1 network.

In CA3, excitatory synapses onto interneurons display different types of synaptic plasticity including NMDA-dependent LTP and NMDAR-independent LTD (Laezza et al., 1999; Laezza and Dingledine, 2004). However, whether synaptic plasticity occurs at synapses onto CA3 SOM interneurons remains to be determined.

In DG, however, excitatory synapses onto both types of SOM interneurons, HIPP and HIL cells, show longterm synaptic plasticity (Yuan et al., 2017). In these cases, plasticity is induced by the application of an associative burst frequency stimulation at $30 \mathrm{~Hz}$ (aBFS) of afferents paired with postsynaptic action potentials, a stimulation protocol aimed at mimicking fast rhythmic neuronal network activity patterns at gamma $(30-100 \mathrm{~Hz})$ frequencies in DG. Remarkably, aBFS induces long-lasting depression (LTD) of excitatory synapses from GC onto HIPP cells, but LTP of excitatory synapses from GC and mossy cells onto HIL cells (Yuan et al., 2017). The increase and the decrease in the failure rate of synaptic transmission accompanying LTD in HIPP cells and LTP in HIL cells, respectively, suggest that both phenomena involve presynaptic expression mechanisms (Yuan et al., 2017). These results indicate that long-term synaptic plasticity in DG HIPP cells differ from that in CA1 OLM cells. Thus, although both cell types provide local dendritic feedback inhibition, their synapses from excitatory inputs display different types of long-term changes, indicating region-specific plasticity properties.

\section{REGULATION OF CA1 NETWORK METAPLASTICITY BY PLASTICITY OF EXCITATORY SYNAPSES OF SOM INTERNEURONS}

As mentioned previously, early work established that afferents of inhibitory interneurons express long-term potentiation (Buzsaki and Eidelberg, 1982). Coupled with the finding that pharmacological inhibition of GABAergic transmission facilitated the induction of LTP at PC excitatory synapses (Wigstrom and Gustafsson, 1983), this led to the concept that plasticity at excitatory synapses in interneurons increase inhibition of PCs and dampen LTP at PC excitatory synapses. However, more recent work indicates that multiple types of synaptic plasticity at excitatory synapses onto inhibitory interneurons have more complex actions in hippocampal networks (Kullmann and Lamsa, 2007; Pelletier and Lacaille, 2008).

\section{Long-Term Plasticity of Excitatory Synapses Controls SOM Interneuron Firing and Synaptic Output}

Dendrite-projecting SOM interneurons provide efficient suppression of CA1 PC dendritic excitatory synaptic inputs and synaptically-evoked burst firing (Lovett-Barron et al., 2012). In vivo during spatial navigation, dendritic inhibition by SOM interneurons suppresses the firing of PCs in their place fields, as well as PC burst firing (Royer et al., 2012). But dendritic inhibition is not static, and the recruitment of recurrent dendritic inhibition in PCs is dynamic during short trains of stimulation (Pouille and Scanziani, 2004). At the onset of a series of stimuli, 
soma- and proximal dendrite-targeting recurrent inhibition are elicited. Later in the series of stimuli, recurrent inhibition is evoked in the distant dendritic regions. Thus, during repetitive activation of PCs, recurrent inhibition switches from transient somatic inhibition to late persistent dendritic inhibition (Pouille and Scanziani, 2004). These dynamic changes in dendritic inhibition are due in part to a late and persistent recruitment on SOM interneuron (OLM cell) firing during short trains of CA1 PC stimulation.

Induction of Hebbian LTP during voltage clamp recordings requires the pairing of presynaptic stimulation with postsynaptic depolarization (Perez et al., 2001). However, during current clamp recordings, presynaptic TBS stimulation alone is sufficient to activate mGluR1a and evoke EPSPs that trigger postsynaptic firing of action potentials in SOM interneurons, and thus, induce Hebbian LTP (Vasuta et al., 2015). Using the TBS induction protocol in slices permits the assessment of the functional impact of Hebbian LTP in SOM interneurons. As synaptic efficacy is improved during Hebbian LTP at excitatory synapses in SOM interneurons, the synaptically-evoked firing of SOM interneurons should show long-lasting increases after Hebbian LTP. Indeed, short trains of afferents stimulation in slices elicit two patterns of evoked firing in SOM interneurons (BiC and OLM cells): an onset-transient firing consistent with activation of CA3 afferents; or a late-persistent firing consistent with activation of CA1 afferents (Croce et al., 2010). After application of the TBS induction protocol for Hebbian LTP, onset-transient responses are unchanged but late-persistent firing responses of SOM interneurons show longterm increases (Croce et al., 2010). These long-term changes in synaptically-evoked firing are prevented by the application of the selective mGluR1 $\alpha$ antagonist LY367385 during the TBS induction (Croce et al., 2010). These results suggest that Hebbian LTP at excitatory synapses translates into an increase in output firing of SOM interneurons (Croce et al., 2010).

Using a similar approach during the whole-cell recording of inhibitory postsynaptic currents (IPSCs) in CA1 pyramidal cells, the TBS induction protocol for Hebbian LTP produces longterm increases in postsynaptic inhibitory responses in pyramidal cells (Lapointe et al., 2004). The long-term increase in inhibition is not accompanied by any change in excitatory postsynaptic response, and is prevented in mGluR1 knockout mice that lack Hebbian LTP in SOM interneurons (Lapointe et al., 2004). These findings suggest that Hebbian LTP at excitatory synapses of SOM interneurons translates in long-term increases in SOM cell firing and pyramidal cell inhibition (Figure 5).

\section{Long-Term Plasticity of SOM Interneuron Excitatory Synapses Controls CA1 Network Metaplasticity}

Synaptic plasticity is bidirectionally modulated by prior cellular and/or synaptic activity, a phenomenon called metaplasticity (plasticity of synaptic plasticity; Bear, 1995). In the hippocampus, long-term plasticity at SC-CA1 PC synapses is regulated by multiple metaplastic mechanisms, including both homo- and hetero-synaptic processes (Abraham, 2008). In CA1, the dendrite-projecting SOM interneurons have emerged as central players in the regulation of the local network metaplasticity. Optogenetic activation of CA1 SOM interneurons (OLM cells) dampens information flow from the entorhinal cortex through the TA pathway via direct inhibition of CA1 PCs distal dendrites, and facilitates information flow from CA3 through the SC pathway via inhibition of other inhibitory interneurons (Leao et al., 2012). In addition, CA1 OLM cells regulate the metaplasticity of TA and SC pathways (Figure 5). Optogenetic activation of OLM cells during LTP induction decreases LTP at TA-PC synapses, whereas it facilitates LTP at SC-PC synapses (Leao et al., 2012).

Since Hebbian LTP at excitatory synapses onto SOM interneurons results in long-term changes in their output firing and inhibition of pyramidal cells, it should also result in longterm regulation of plasticity at SC and TA synapses onto PCs (Figure 5). Indeed, application of the TBS induction protocol for Hebbian LTP in SOM interneurons does not affect basal transmission at SC-PC synapses, but increases the magnitude of LTP at SC-PC synapses elicited $30 \mathrm{~min}$ later (Vasuta et al., 2015). This facilitation of LTP at SC-PC synapses is prevented by optogenetic silencing of SOM interneurons during the TBS induction protocol, or by the mGluR $1 \alpha$ antagonist LY367385, suggesting that Hebbian LTP in SOM interneurons result in long-term upregulation of plasticity of SC-PC synapses (Vasuta et al., 2015). Likewise, application of the induction protocol for mGluR1-dependent late LTP $\left(\mathrm{L}-\mathrm{LTP}_{\mathrm{mGluR} 1}\right)$ in SOM interneurons facilitates LTP of SC-PC synapses elicited $2 \mathrm{~h}$ later (Artinian et al., 2019). This persistent facilitation of LTP at SC-PC synapses is absent in mice with conditional knock-out of Rptor in SOM interneurons that lack L-LTP ${ }_{\mathrm{mGluR} 1}$, suggesting that long-term upregulation of plasticity of SC-PC synapses lasting hours results from late-LTP at excitatory synapses onto SOM interneurons (Artinian et al., 2019). De-phosphorylation of the eukaryotic initiation factor $2 \alpha$ subunit $(\mathrm{eIF} 2 \alpha)$ by synaptic activity is a key regulator of mRNA translation and late-LTP in PCs (Costa-Mattioli et al., 2007). Knock-in mice with a mutated non-phosphorylatable eIF $2 \alpha\left(\right.$ eIF $\left.2 a^{\text {S51A }}\right)$ show facilitation of late-LTP in CA1 PCs (Costa-Mattioli et al., 2007). Interestingly, conditional knock-in of eIF $2 \alpha^{\text {S51A }}$ specifically in SOM interneurons, upregulates mRNA translation in SOM interneurons, reduces inhibitory synaptic transmission in CA1 PCs, and facilitates induction of L-LTP at SC-PC synapses (Sharma et al., 2020). Altogether these findings suggest that synaptic plasticity at excitatory synapses of SOM interneurons acts as a long-term metaplasticity switch at SC-PCs synapses via disinhibition (Figure 5).

Similarly, long-term plasticity at excitatory synapses of SOM interneurons may also regulate metaplasticity of TA synapses of PCs. Application of the TBS induction protocol for Hebbian LTP in SOM interneurons does not affect basal transmission at TA-PC synapses but decreases the magnitude of LTP that is elicited $30 \mathrm{~min}$ later at these synapses (Sharma et al., 2020). Importantly, this down-regulation of LTP at TA-PC synapses is increased in mice with conditional knock-in of the non-phosphorylatable eIF2a ${ }^{\text {S51A }}$ in SOM interneurons that result 
A

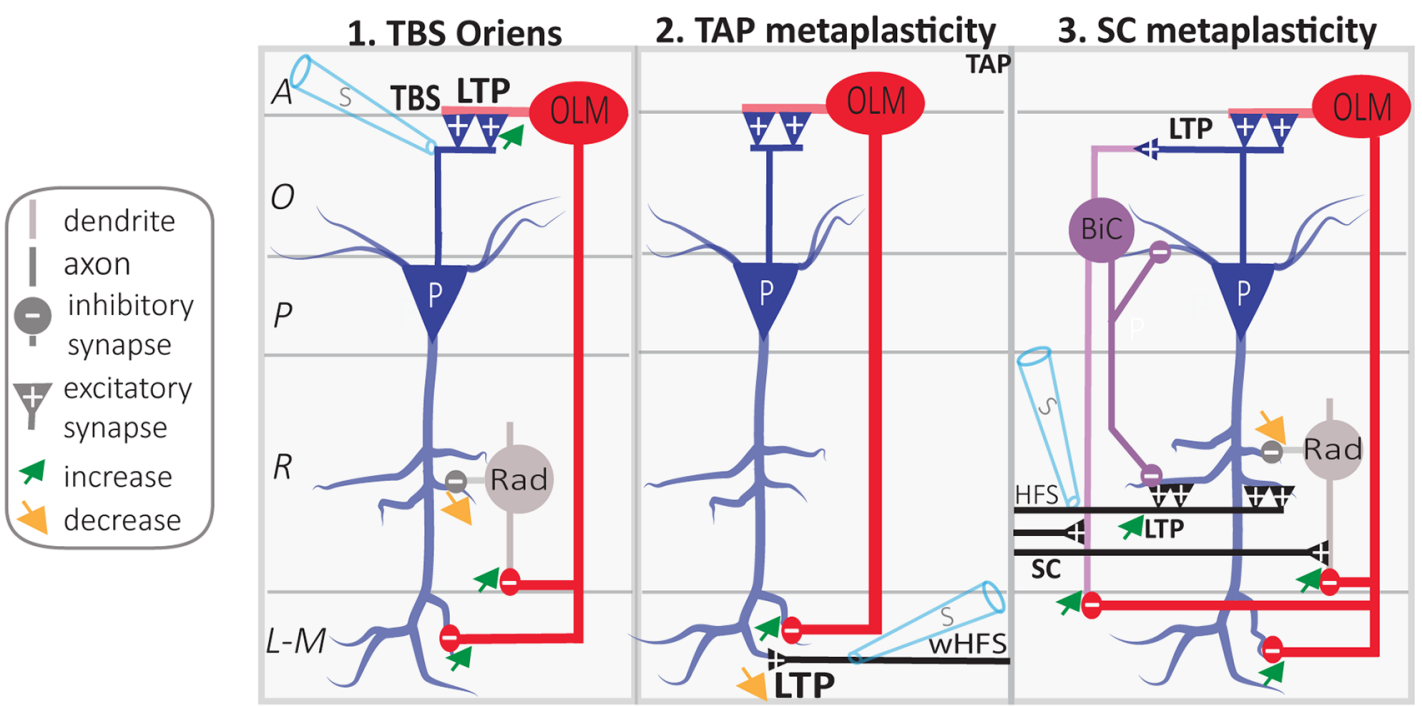

B

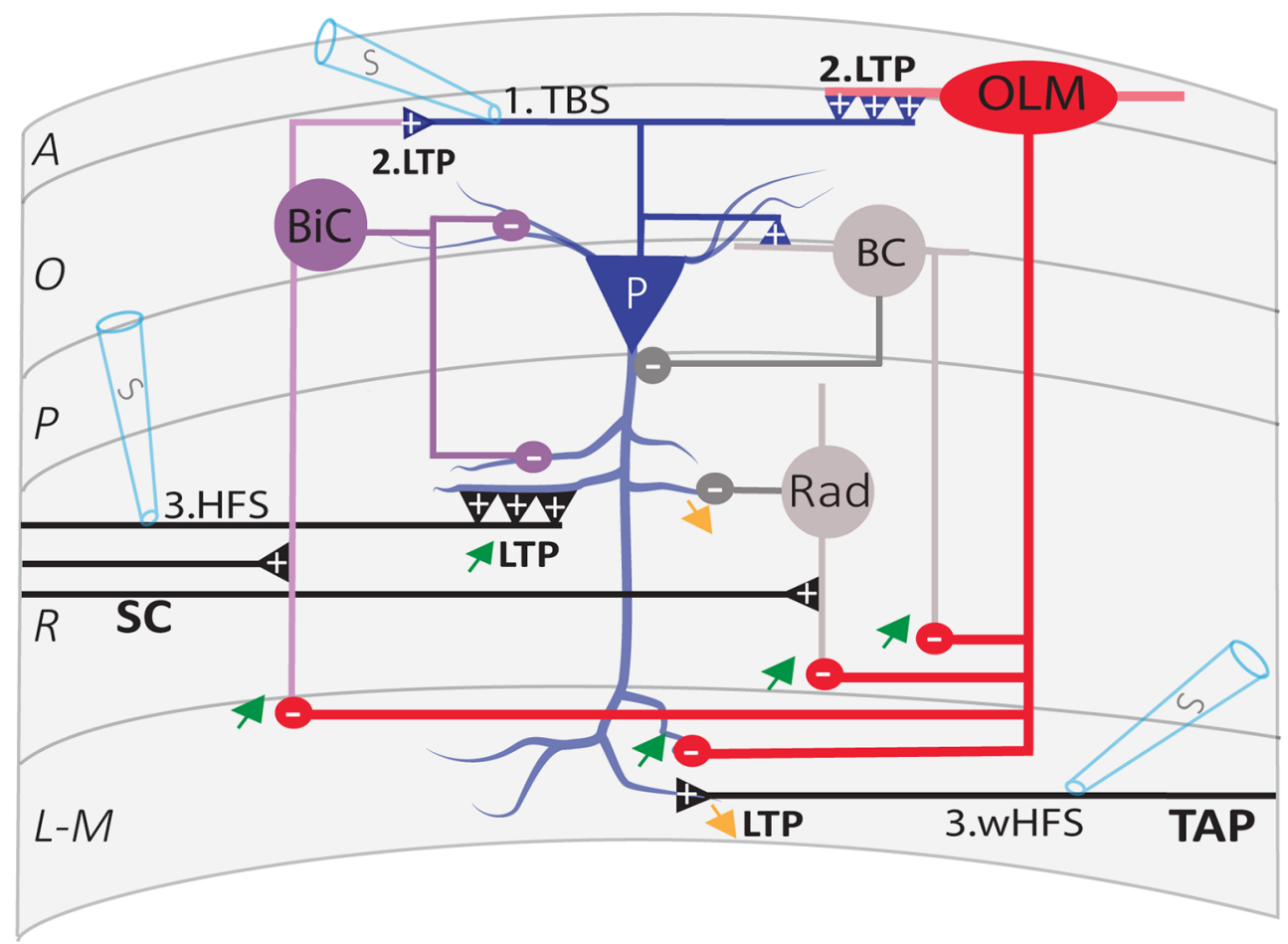

FIGURE 5 | Regulation of CA1 network metaplasticity by plasticity at excitatory synapses of SOM interneurons. (A) Diagrams of synaptic plasticity of SOM interneurons and regulation of CA1 network. (A1) Theta burst stimulation (TBS) at the O/A border induces LTP of CA1 PC synapses onto SOM interneurons (OLM cell). LTP at input synapses results in an increased firing of OLM cell, which leads to increased postsynaptic inhibition of (i) PC distal dendrites and (ii) radiatum interneurons (rad). This leads to the increased inhibition of distal dendrites in stratum lacunosum-moleculare (L-M), and disinhibition of more proximal dendrites in stratum radiatum (R). (A2) LTP of excitatory inputs of OLM cell results in TA pathway metaplasticity. Because of distal dendritic inhibition increase, tetanization of the temporoammonic (TA) pathway produces less LTP at TA-PC synapses. (A3) LTP of excitatory inputs of OLM cell results in SC pathway metaplasticity. Because of proximal dendritic disinhibition, tetanization of Schaffer collaterals (SC) produces larger LTP at SC-PC synapses. As electrically induced TBS also produces LTP at PC-BiC synapses, the overall results on BiC inhibition of PCs remain undetermined. (B) Integration of synaptic mechanisms described above: 1. TBS of PC axons; 2. LTP at PC-OLM synapses results in more inhibition of distal PC dendrites and disinhibition of proximal PC dendrites; the end-result of LTP at PC-BiC synapses on BiC inhibition of PC remains undetermined. 3. Metaplastic changes of CA1 circuit: increased LTP at SC-PC synapses and decreased LTP at TA-PC synapses. Abbreviations for CA1 layers: A, alveus; O, oriens; P, pyramidale; R, radiatum; L-M, lacunosum-moleculare. Abbreviations for CA1 afferent inputs: SC, Schaffer collateral pathway; TAP, temporo-ammonic pathway. Abbreviations for SOM cell types: (red) OLM, oriens/lacunosum-moleculare cell; (violet) BiC, bistratified cell. Abbreviations for other cell types: (blue) P, pyramidal cell; (gray) BC, basket cell; (gray) Rad, unidentified stratum radiatum interneurons. Other Abbreviation: S, stimulation electrode. 
in upregulated mRNA translation in these cells and impaired inhibition of PCs (Sharma et al., 2020). Thus, long-term plasticity at excitatory synapses of SOM interneurons may act as a bidirectional long-term metaplasticity switch in the CA1 network to differentially regulate long-term plasticity of SC and TA synapses of PCs (Figure 5).

\section{SOM INTERNEURONS IN HIPPOCAMPUS-DEPENDENT LEARNING AND MEMORY}

At the behavioral level, the dendritic inhibition mediated by SOM interneurons plays a key role in hippocampusdependent learning and memory (Lovett-Barron et al., 2014). The contribution of SOM interneurons has been studied particularly in the dorsal part of CA1, in relation to the encoding of spatial and contextual memory by PCs.

A combination of in vivo calcium imaging with pharmacogenetic and optogenetic manipulations of SOM interneurons in the CA1 hippocampus of mice revealed that dendritic inhibition by SOM interneurons is necessary for contextual fear memory formation (Lovett-Barron et al., 2014). During contextual conditioning, aversive stimuli activate, via septal cholinergic inputs, SOM interneurons that target PC dendrites. The activation of SOM interneurons leads to inhibition of PC distal dendrites that receive aversive sensory excitation from the entorhinal cortex (Lovett-Barron et al., 2014). Inactivating dendrite-targeting SOM interneurons during aversive stimuli increases PC responses and prevents fear learning (Lovett-Barron et al., 2014). Thus, activation of dendritic inhibition by SOM interneurons may be a mechanism for the exclusion of aversive stimuli from hippocampal contextual representations that is necessary during fear learning (LovettBarron et al., 2014).

Interestingly, GABAergic cells from the brainstem nucleus incertus (NI) selectively inhibit hippocampal SOM interneurons directly, and indirectly by inhibiting septal excitatory inputs to SOM interneurons (Szonyi et al., 2019). NI GABAergic inputs to the hippocampus are activated by relevant salient environmental stimuli in vivo (Szonyi et al., 2019). In addition, optogenetic manipulations of NI GABAergic neurons during contextual fear conditioning modify the strength of contextual fear memory: activation of NI GABA neurons impairs, whereas inhibition improves contextual fear memory (Szonyi et al., 2019). Thus, SOM interneuron gating of PC TA sensory inputs during contextual learning may be regulated by the brainstem NI inhibitory system.

\section{Long-Term Plasticity of SOM Interneuron Excitatory Synapses in Learning and Memory}

Cell-specific transgenic mouse approaches were used to test whether there is a functional role of long-term plasticity at SOM interneuron excitatory synapses in hippocampal learning and memory (Artinian et al., 2019). Downregulation of mTORC1 activity was achieved by cell-specific conditional knock-down of the gene for the essential mTORC1 component Rptor in SOM interneurons, whereas upregulation of mTORC1 activity was attained by cell-specific conditional knock-down of the mTORC1 repressor Tsc1 gene. At the behavioral level, loss of mTORC1 function specifically in SOM interneurons impaired contextual fear and spatial long-term memories, but spared sensory-motor gating, hippocampusdependent short-term contextual memory, and hippocampusindependent long-term auditory-cued fear memory (Artinian et al., 2019). In contrast, upregulation of mTORC1 activity specifically in SOM interneurons augmented spatial and contextual fear memories, and impaired discrimination (Artinian et al., 2019).

As mentioned before, at the cellular level, bidirectional regulation of mTORC1 activity in SOM interneurons differentially regulates mGluR1-mediated late-LTP at SOM interneurons excitatory synapses, whereas at the network level, the SOM interneuron late-LTP induction protocol upregulates metaplasticity of the SC pathway in PCs, in a mTORC1-dependent manner. Moreover, using ex vivo whole-cell recordings after training, contextual fear learning was found to persistently increase the efficacy of excitatory synapses of SOM interneurons via mGluR1 and mTORC1. These findings link mTORC1 to learning-induced long-term plasticity of SOM interneuron excitatory synapses, regulation of CA1 network metaplasticity, and hippocampal long-term memory consolidation (Artinian et al., 2019). Thus, long-term plasticity at SOM interneuron excitatory synapses may play a role in spatial/contextual information encoding by CA1 PCs, by promoting on a long timescale the internal representations by the hippocampal CA3 pathway while dampening external representations via the extrahippocampal entorhinal inputs (Artinian et al., 2019).

Recent work manipulating another pathway to enhance memory, de-phosphorylation of the translation initiation factor eIF2 $\alpha$ (Costa-Mattioli et al., 2007), further support the idea that SOM interneurons synaptic plasticity is important for memory formation (Sharma et al., 2020). Contextual fear learning reduces the phosphorylation of eIF $2 \alpha$ in hippocampal PCs and SOM interneurons, but not in PV interneurons (Sharma et al., 2020). Moreover, cell-specific conditional knock-in of the non-phosphorylatable eIF $2 \alpha^{\mathrm{S} 1 \mathrm{~A}}$ in PCs or in SOM interneurons upregulates general mRNA translation in these cells and is sufficient to increase long-term contextual fear memory (Sharma et al., 2020). Silencing CA1 SOM interneurons, using the inhibitory designer receptor exclusively activated by designer drug (DREADD), during the consolidation of fear memory, reverses the increase in contextual fear memory in the SOM interneurons conditional knock-in mice (Sharma et al., 2020), indicating that hippocampal CA1 SOM interneurons are pivotal for memory consolidation. As mentioned above, these behavioral changes suggest that a reduction in eIF $2 \alpha$ phosphorylation in SOM interneurons promotes memory formation via two mechanisms; first, it increases the responsiveness of PCs to SC inputs by disinhibition and thereby facilitates LTP at these synapses; and second, it suppresses LTP in the TA pathway, thereby modulating sensory inputs from the entorhinal cortex 
(Sharma et al., 2020). These findings suggest the existence of two autonomous and complementary memory consolidation processes mediated by eIF $2 \alpha$-dependent translational control in PCs and SOM interneurons: (i) translational changes in excitatory PCs help to facilitate memory consolidation by mediating synaptic plasticity in a sparse population of CA1 PCs; and (ii) translational changes in SOM interneurons facilitate memory consolidation by gating synaptic plasticity in the CA1 PCs circuit.

\section{Dorso-Ventral Differences in SOM Interneuron Function}

The research reviewed so far on CA1 SOM interneurons and hippocampal function has been mostly concerned with interneurons of the dorsal hippocampus. However, recent work suggests differences in the function of CA1 SOM interneurons along the dorsoventral hippocampal axis (Siwani et al., 2018). Targeted expression of optogenetic tools in CA1 OLM cells expressing the nicotinic receptor $\alpha 2$ subunit $(\mathrm{OLM} \alpha 2)$ was used to activate or silence these cells in freely moving mice during contextual passive avoidance tasks and novel object recognition (Siwani et al., 2018). Activation of intermediate CA1 OLM $\alpha 2$ interneurons during passive avoidance learning impairs aversive memory, whereas silencing of OLM $\alpha 2$ cells has no effect. In contrast, silencing of dorsal CA1 OLM $\alpha 2$ interneurons impairs aversive memory (Siwani et al., 2018). For object recognition, silencing of intermediate CA1 OLM $\alpha 2$ interneurons during training enhances object memory, while their activation impairs it. In contrast, silencing dorsal CA1 OLM $\alpha 2$ cells has no effect on object memory (Siwani et al., 2018). To summarize, in contrast to dorsal CA1, intermediate CA1 OLM $\alpha 2$ cell activity is not required for contextual fear memory. However, their activation reduces both contextual fear and object memory (Siwani et al., 2018). Thus, intermediate OLM $\alpha 2$ cells can modulate object or fear-related representations. These findings suggest that intermediate OLM $\alpha 2$ cells may be silenced during fear memory formation, meaning that in the intermediate CA1, the inputs from the TAP to CA1 PCs may not be dampened in the learning process. This is consistent with the memory impairment induced by the optogenetic activation of these cells during the aversive stimuli presentation or during object exploration (Siwani et al., 2018). Alternatively, the memory impairment induced by intermediate OLM $\alpha 2$ cell activation may mean that proper memory formation requires the activation of a sparse number of cells and that optogenetic stimulation activates many of them. Interestingly, intermediate OLM $\alpha 2$ cells display increased sensitivity for acetylcholine compared to dorsal CA1 OLM $\alpha 2$ cells which could mean that these cells are more entrained by septal inputs and play a role in timing the inputs onto CA1 PCs. Thus, activating intermediate OLM $\alpha 2$ cells with optogenetics could have disrupted the proper convergence of inputs. Lastly, the increase of object recognition following intermediate OLM $\alpha 2$ cell inhibition during object exploration could indicate that their role is to gate the size of the engram encoding object memory, as seen in other hippocampal areas (see below, Stefanelli et al., 2016), and inhibiting these cells would lead to a stronger but less precise memory.

The role of SOM interneurons in contextual fear memory also appears different in the dentate gyrus (DG) than in the dorsal CA1 hippocampus (Stefanelli et al., 2016). Silencing DG SOM interneurons with inhibitory DREADD, during contextual fear conditioning, increases contextual fear memory and the size of the c-Fos expressing granule cell engram (Stefanelli et al., 2016). Activation of DG SOM interneurons using excitatory DREADD during contextual fear training, impairs contextual fear memory and reduces the number of c-Fos expressing granule cells (Stefanelli et al., 2016). Thus, DG SOM interneurons, most likely HIPP cells, may gate the size of the DG neuronal ensemble encoding contextual memory via dendritic lateral inhibition of granule cells (Stefanelli et al., 2016).

\section{SOM Interneurons and Place Cells}

During spatial exploration, a subset of dorsal CA1 pyramidal cells progressively displays increased firing when the animal approaches a specific location. Each place cell demonstrates a preference for a different location (place field; O'Keefe and Dostrovsky, 1971). Place cells are characterized by a slow ramp-like depolarization of membrane potential $(\mathrm{Vm})$ driving increased AP discharge when the animal passes through the place field (Harvey et al., 2009; Lee et al., 2012; Bittner et al., 2015). The fluctuations in PCs Vm drive their output firing, and the formation of place cells is mediated by synaptic potentiation of a specific subset of excitatory inputs (Bittner et al., 2015; Sheffield et al., 2017). In CA1 PCs, dendritic plateau potentials are generated by the coincident activation of CA3 and entorhinal cortex inputs, leading to increased output firing and LTP of perforant path synapses (Takahashi and Magee, 2009), and the induction of place field in PCs (Bittner et al., 2015).

Inhibitory interneurons play a cardinal role in achieving input selectivity necessary to drive place cells output firing (Grienberger et al., 2017). Optogenetic silencing of CA1 SOM or PV interneurons, or both populations, in awake head-fixed mice, performing a spatial navigation task increases PCs output firing in their place fields, without affecting their firing rate out-of-field (Royer et al., 2012; Grienberger et al., 2017). This is consistent with the dendrite-targeting interneurons role in regulating complex spiking and perisomatic-targeting interneurons regulating AP timing (Royer et al., 2012). Thus, inhibitory interneurons may be critical during place cell firing by controlling their excitatory inputs, by limiting dendritic amplification and suppressing out-of-field excitatory inputs (Grienberger et al., 2017). By that mean, SOM interneurons participate in the control of the plasticity of specific relevant inputs (Takahashi and Magee, 2009).

Recent works in vivo revealed that CA1 PCs exhibit place field plasticity following the initiation of dendritic plateau potentials occurring naturally in behaving mice or induced artificially by the injection of a depolarizing current through the recording pipette (Bittner et al., 2015, 2017). This synaptic plasticity is termed behavioral timescale synaptic plasticity (BTSP), in which active excitatory inputs within seconds before or after the generation of dendritic plateau potentials are selectively 
potentiated, contrary to the classical Hebbian plasticity in which a coincident activation of the presynaptic and the postsynaptic neuron within a narrow time window is required (Bittner et al., 2017; Magee and Grienberger, 2020). BTSP can be induced ex vivo in hippocampal acute slices by pairing stimulations of the presynaptic input with dendritic plateau potential in the postsynaptic $\mathrm{PC}$, is pathway-specific, and requires the activation of NMDAR and L-type $\mathrm{Ca}^{2+}$ channels (Bittner et al., 2017; Magee and Grienberger, 2020). Interestingly, during spatial navigation, when an animal transits from familiar to a new environment, SOM interneurons-mediated dendritic inhibition transiently decreases which causes a short-lasting increase in PCs dendritic excitability, whereas during the same period, PV interneuronsmediated perisomatic inhibition increases (Sheffield et al., 2017; Sheffield and Dombeck, 2019). Notably, the transient decrease in dendritic inhibition may serve as a time window in which increased dendritic plateau potentials in PCs promotes synaptic potentiation to occur in selective inputs to drive place output firing once the inhibitory system recovers in the familiar environment.

Hence, SOM interneurons have a determining role in place field formation by regulating dendritic plateau potentials and synaptic plasticity induction in selective excitatory inputs necessary for network adaptation to environmental changes.

\section{SOM INTERNEURONS AND ASTROCYTES}

In addition to pre- and post-synaptic neurons, glial cells and particularly astrocytes can actively modulate synaptic transmission in hippocampal circuits through bidirectional communication with neurons. The term "tripartite synapse" (Araque et al., 1999) encompasses the structural enwrapping of the synaptic cleft that allows astrocytes to sense neuronal activity through membrane receptors, leading to spatiotemporally coordinated fluctuations of intracellular $\mathrm{Ca}^{2+}$ levels and their ability to trigger gliotransmitters release (Araque et al., 2014; Bazargani and Attwell, 2016; Durkee and Araque, 2019). Despite multiple interactions between inhibitory networks and excitatory circuits (Klausberger and Somogyi, 2008), the current understanding of the bidirectional communications between neurons and astrocytes has emerged mainly from studies focusing on excitatory transmission leaving their involvement at inhibitory synapses ill-defined (Losi et al., 2014). However recent studies indicate that astrocytes also interact dynamically with inhibitory interneurons.

Through expression of GABA receptors $\left[\mathrm{GABA}_{\mathrm{A}}\right.$ Rs (Egawa et al., 2013; Ishibashi et al., 2019) and GABA $_{B}$ Rs (Kang et al., 1998; Serrano et al., 2006; Ding et al., 2009; Haustein et al., 2014; Ishibashi et al., 2019)] and transporters (GAT-1 and GAT-3; Borden and Caplan, 1996; Ribak et al., 1996; Ishibashi et al., 2019), astrocytes can detect and respond to GABAergic activity with $\mathrm{Ca}^{2+}$ oscillations (Nilsson et al., 1993; Lia et al., 2019). Astrocytic GABAergic $\mathrm{Ca}^{2+}$ activities are mediated by several mechanisms involving voltage-sensitive $\mathrm{Ca}^{2+}$ channels, release from internal stores, G proteins, GATs, and sodium/calcium exchangers (NCXs; Perea et al., 2016; Ishibashi et al., 2019; Mederos and Perea, 2019; Lia et al., 2019). GABAergic activation

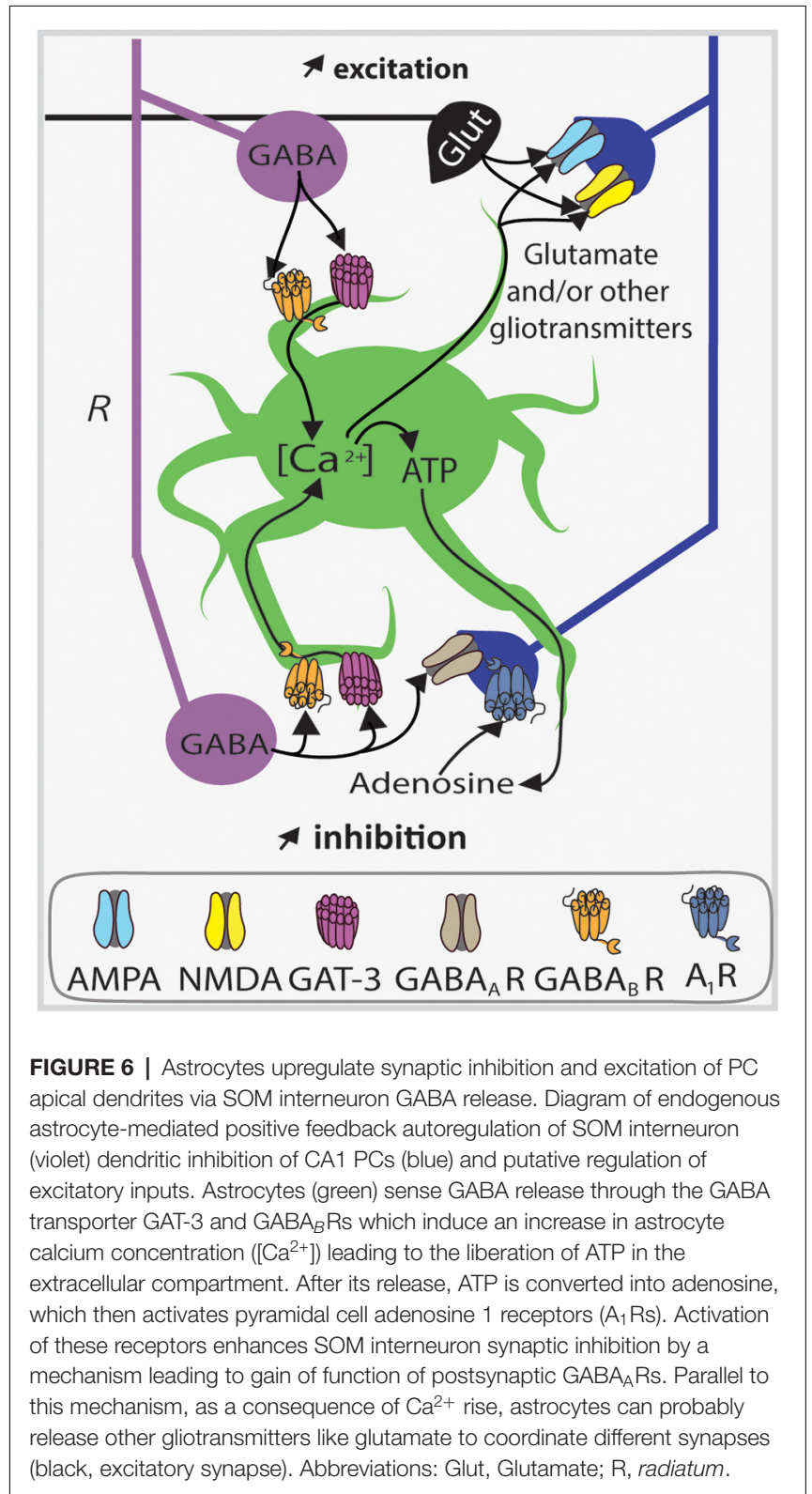

of astrocytes can lead to the release of various gliotransmitters such as glutamate (Kang et al., 1998; Andersson et al., 2007; Mariotti et al., 2016; Perea et al., 2016; Mederos and Perea, 2019), GABA (Lee et al., 2010; Yoon et al., 2011), ATP (Serrano et al., 2006; Boddum et al., 2016; Covelo and Araque, 2018; Matos et al., 2018) or efflux of chloride (Egawa et al., 2013) to modulate both excitatory and inhibitory transmission (Figure 6; Perea et al., 2016). While the heterogeneity of interneurons subtypes can give rise to diverse GABAergic signaling, we focus here on the interplay between hippocampal SOM interneurons, PCs, and astrocytes.

Intense depolarization of astrocytes induces $\mathrm{Ca}^{2+}$ increases that potentiate miniature inhibitory postsynaptic currents (mIPSCs) in pyramidal cells (Kang et al., 1998), that could originate at least in part from SOM interneurons with axons 
in stratum radiatum (e.g., BiC). In addition, calcium uncaging in hippocampal astrocytes leads to an increase in spontaneous inhibitory postsynaptic currents (sIPSCs) frequency in stratum radiatum interneurons, which is induced by astrocytic glutamate release targeting kainate receptors on PCs (Liu et al., 2004). These studies show that astrocytes are well suited to establish another level of connection and regulation between inhibitory and excitatory networks in the hippocampus. Indeed GABAergic activation of hippocampal astrocytes was found to induce the release of ATP, which is converted extracellularly into adenosine in order to activate presynaptic adenosine $A_{1}$ receptors $\left(A_{1} R\right)$ on $P C s$ in the context of heterosynaptic depression at excitatory synapses of CA1 PCs (Serrano et al., 2006). This demonstrated a functional interplay between glial and GABAergic neuronal networks during heterosynaptic plasticity.

More recently, the use of optogenetic tools (Goshen, 2014) allowed the specific stimulation of different subtypes of interneurons to decipher the complex modulatory mechanisms of inhibitory synapses. In acute hippocampal slices, astrocytes specifically upregulate synaptic inhibition of PCs by SOM interneurons but not PV interneurons (Matos et al., 2018). Using the cell-specific expression of channelrhodopsin-2 in SOM or $\mathrm{PV}$ interneurons, optogenetic activation of SOM interneurons (evoking one or two action potentials) was found to induce $\mathrm{Ca}^{2+}$ activities in astrocyte processes mediated by $\mathrm{GABA}_{\mathrm{B}} \mathrm{R}$ and GAT-3 (Figure 6; Matos et al., 2018). This in turn leads to the astrocytic release of ATP, converted extracellularly into adenosine that acts on postsynaptic $A_{1} R$ to upregulate $S O M$ interneuron inhibition onto PCs (Figure 6). This suggests an endogenous astrocyte-mediated positive feedback autoregulation of SOM interneuron dendritic inhibition of PCs (Matos et al., 2018). Importantly, this mechanism may be specific to SOM interneuron synapses as blockers of $\mathrm{A}_{1} \mathrm{R}$ (DPCPX) or GAT-3 (SNAP-5114) failed to affect IPSCs evoked in PCs by optogenetic activation of PV interneurons (Matos et al., 2018). In addition, spontaneous synaptic inhibition (sIPSC) in PCs (which reflects more global inhibition of PCs coming from many interneurons subtypes), was depressed by inhibition of $A_{1} R$, GAT-3, or astrocytic $\mathrm{Ca}^{2+}$ oscillations (Matos et al., 2018). These findings point toward the possible existence of multiple astrocytemediated modulations of synaptic inhibition originating from different interneuron subtypes.

Consistent with this concept, other groups have shown different astrocyte modulation based on interactions with specific interneuron subtypes. Optogenetic activation of CA1 hippocampal astrocytes in slices increases the firing rate of CCK interneurons, but not PV interneurons, dependent on the release of ATP acting on P2Y-1R which leads to inhibition of a two-pore domain potassium channel (K2P; Tan et al., 2017). In contrast, optogenetic activation of astrocytic ATP release induces hyperpolarization of PCs mediated by its conversion into adenosine acting on $A_{1} R$ (Tan et al., 2017). Interestingly in the neocortex, astrocyte $\mathrm{Ca}^{2+}$ elevations are differentially modulated by GABAergic signaling originating from PV or SOM interneurons. Optogenetic activation of PV interneurons induces weak $\mathrm{Ca}^{2+}$ elevations whereas SOM interneuron activation results in robust $\mathrm{GABA}_{\mathrm{B}}$ receptor-mediated $\mathrm{Ca}^{2+}$ elevations (Mariotti et al., 2018). Moreover, these astrocyte $\mathrm{Ca}^{2+}$ responses present a form of plasticity, with depression of $\mathrm{Ca}^{2+}$ elevations upon repetitive PV interneuron stimulations and enhancement after repetitive SOM interneuron stimulations. The latter relies on somatostatin released by SOM interneurons acting on somatostatin receptors along with astrocytic processes (Mariotti et al., 2018).

Taken together these results show that astrocytes dynamically influence both the input and output of inhibitory interneurons, notably SOM interneurons, and thus, astrocytes do not have only a passive role in inhibitory circuits, similarly to their contribution to excitatory circuits. Astrocytes are at the interface between excitatory and inhibitory synapses, and more detailed and comprehensive studies in situ and in vivo are required to refine our understanding of the inhibitory-glial-excitatory networks interplay involving SOM interneurons and its role in hippocampal synaptic plasticity and function.

\section{SOM INTERNEURONS IN DISEASE}

Given that hippocampal synaptic function and plasticity are impaired in brain disease with cognitive disorder, notably Alzheimer's disease (AD), SOM interneuron dysfunction may also contribute to these cognitive impairments.

In his initial observations after the death of the patient A. Deter suffering from dementia, Alois Alzheimer identified two characteristic cerebral lesions, neurofibrillary tangles made of Tau and senile plaques consisting of $A \beta$ peptide aggregation (Graeber et al., 1997). Accumulation of $A \beta_{1-42}$ oligomers is one of the earliest events leading to direct or indirect synaptic alterations in AD (Huang and Mucke, 2012; Mucke and Selkoe, 2012). Electron microscopy and immunohistochemistry quantifications reported a significant decrease of synaptic density in the hippocampus of AD patients (Davies et al., 1987; Masliah et al., 2001). There is also a strong correlation between $A \beta$ load in the patient brain and the extent of synapse loss (Wang et al., 1999). However, in many animal models of AD, despite cognitive alterations, these dendritic spine losses are not always present or as pronounced as in the human form of the disease (Auld et al., 2002; Elder et al., 2010). Accordingly, previous works have shown that different neuronal populations such as excitatory neurons vs. inhibitory interneurons, are differentially affected (Davies et al., 1980; Ramos et al., 2006). Moreover, inhibitory interneuron damage may occur before principal neuron alterations and the manifestation of symptoms. Focusing on SOM interneurons, a selective and early neurodegeneration of O-LM and HIPP cells was reported (Ramos et al., 2006). In the APP/PS1 transgenic mouse model of $\mathrm{AD}$, several features of these SOM interneurons are altered. Using quantitative RTPCR, SOM mRNA level is decreased as early as 4 months of age. Quantification of SOM interneurons showed a 60\% reduction in cell numbers and the presence of dystrophic SOM interneurons in transgenic compared to wildtype animals (Ramos et al., 2006). Importantly, these alterations precede PC loss. Moreover, SOM interneuron modifications showed a linear relationship with $\mathrm{A} \beta$ presence/concentration indicating that SOM interneuron loss 
is an early hippocampal neuropathology in this mouse model of $\mathrm{AD}$.

Functional alterations of hippocampal SOM interneurons also accompany the early neuropathological changes in the $\mathrm{AD}$ mouse model. In an elegant in vivo study taking advantage of Gad1-eGFP mice crossbred with APP/PS1AD mouse model, structural changes consisting of SOM interneuron axon losses were observed at 4 months of age (Schmid et al., 2016). Moreover, chronic imaging of individual eGFP positive O-LM cells revealed that the normal age-dependent increase in the number of SOM interneuron dendritic spines is impaired in APP/PS1 mice. As for excitatory neurons (Koffie et al., 2009; Wei et al., 2010), the reduction in SOM interneuron spine density was correlated with $A \beta$ proximity $(<50 \mu \mathrm{m})$. Nevertheless, spine stability was impaired in APP/PS1 mice with a greater spine turnover associated with $A \beta$ distance. These structural modifications may represent primary mechanisms to cope with pathological alterations of synapses during AD (Schmid et al., 2016). However, contextual fear learning-associated plasticity of dendritic spines of SOM interneurons is also affected in APP/PS1 mice. In vivo imaging showed that, after contextual fear conditioning, the gain of SOM interneuron dendritic spines is impaired in APP/PS1 mice, and this is associated with impaired contextual fear memory, compared to control mice (Schmid et al., 2016). Based on the cholinergic input that O-LM cells receive from the medial septum during aversive stimuli (Lovett-Barron et al., 2014) and the well-documented cholinergic degeneration in AD (Auld et al., 2002; Perez et al., 2007), the reduction in spine formation could be an indirect result of presynaptic cholinergic deficits. Using imaging with GCaMP6m calcium indicator, delivery of aversive air puffs in awake head-fixed mice evoked reduced $\mathrm{Ca}^{2+}$ responses in putative O-LM cells of APP/PS1 mice (Schmid et al., 2016). These observations are consistent with the observed reduction of medial septum trans-synaptically labeled monosynaptic afferents to SOM interneurons in APP/PS1 mice. In addition, pharmacological blockade of mlAChR or chemogenetic silencing of SOM interneurons during fear conditioning was sufficient to mimic the spine gain reduction and impair fear memory in control mice. Conversely, application of the mlAChR agonist Cevimeline during fear conditioning restored fear memory in APP/PS1 mice (Schmid et al., 2016). These findings demonstrate that early alterations in SOM interneuron spine plasticity may be linked to behavioral impairment and memory loss in AD. Thus, targeting presynaptic inputs or postsynaptic SOM interneurons may offer complementary therapeutic strategies. Indeed, strategies targeting somatostatin receptor subtype- $4\left(\mathrm{SST}_{4} \mathrm{R}\right)$ with agonists have recently been proposed to promote and restore the expression of altered subcortical mRNA genes in AD (Sandoval et al., 2019).

Another key function of SOM interneurons is their involvement in the generation of theta rhythms, which among other hippocampal network oscillations are impaired in AD models (Villette et al., 2010; Palop and Mucke, 2016; Mondragon-Rodriguez et al., 2018). An alternative to transgenic $\mathrm{AD}$ models is to inject directly soluble oligomers of $\mathrm{A} \beta$ peptide $(\mathrm{A} \beta \mathrm{o})$. Recently, co-injection of $\mathrm{A} \beta \mathrm{o}$ and AAV5-Efla-DIO-
hChR2(ET/TC)-mCherry to SST-Cre mice hippocampi was shown to replicate theta oscillations impairments (Villette et al., 2010; Palop and Mucke, 2016), and optogenetic activation of SOM interneurons restored the power of theta oscillations in A $\beta$ o injected animals (Chung et al., 2020). In addition, A $\beta o$ injection desynchronized SOM interneuron firing relative to theta oscillations, which was restored by optogenetic activation of SOM interneurons (Chung et al., 2020). Finally, in slices from Aßo-injected animals, optogenetic stimulation of SOM interneurons enhances sIPSCs received by CA1 PCs at theta frequencies (Chung et al., 2020). Together with the reported loss of SOM interneurons in the perirhinal cortex of $\mathrm{AD}$ patients correlated with A $\beta$ load (Sanchez-Mejias et al., 2020), these findings suggest that targeting SOM interneurons may help restore network oscillations, which are heavily impacted during AD (Palop and Mucke, 2016). Interestingly, transplantation of interneuron progenitors can restore learning and memory in APOE4-KI mice in the presence of $\mathrm{A} \beta$ (Tong et al., 2014). Thus, maintaining proper SOM interneurons synaptic function and plasticity could be crucial to reduce the impact of $\mathrm{AD}$ on cognitive functions, as soon as $\mathrm{A} \beta$ production starts, or even later.

\section{CONCLUSIONS AND FUTURE DIRECTIONS}

The rapid pace of development of new experimental tools for cell-specific identification and manipulation of distinct neuron types will likely provide the means to address many interesting questions that remain unresolved about long-term plasticity at excitatory synapses of SOM interneurons and its role in hippocampal memory processes.

As mentioned above, hippocampal SOM interneurons are part of a group composed of many different cell types, even in a specific hippocampal region like CA1 (Pelkey et al., 2017). Presently, studies on synaptic plasticity of SOM interneurons have focused largely on CA1 BiC and OLM cells (Perez et al., 2001; Lamsa et al., 2007). However, other types of SOM interneurons include cells with both local and longrange projections (DP, BP, and ORP cells; Gulyas et al., 2003; Goldin et al., 2007; Jinno et al., 2007). The DP cells that project to the septum, as well as other hippocampal areas, may be particularly interesting to investigate given the crucial role of septal afferents to the hippocampus during spatial and contextual learning (Lovett-Barron et al., 2014; Schmid et al., 2016). Coupling of trans-synaptic monosynaptic labeling with DP cell-specific identification could be used to characterize and manipulate their excitatory synapses and potential longterm plasticity. It would be of interest to determine how the plasticity of DP interneuron excitatory synapses may play a role in coordinating changes across septal and hippocampal areas during hippocampal learning.

Another interesting issue is the regional difference in the function of SOM interneurons in hippocampal learning, and particularly that of OLM cells along the CA1 dorsoventral axis (Lovett-Barron et al., 2014; Siwani et al., 2018). The different roles of OLM cells in hippocampal learning were suggested to 
be due to a difference in septal cholinergic inputs along the dorsoventral axis (Siwani et al., 2018). As long-term plasticity of SOM interneuron synapses in hippocampal learning has been examined mostly in the dorsal hippocampus (Artinian et al., 2019), it would be of interest to examine if there is a difference in SOM interneuron long-term synaptic plasticity along the dorsal-ventral axis, and if so, does it parallel the difference in the functional role of SOM interneurons in hippocampal learning.

Much progress has been achieved on characterizing Hebbian and mGluR1-mediated LTP at excitatory synapses of SOM interneurons, and its role in the regulation of hippocampal network and memory (Artinian et al., 2019). However other types of long-term synaptic plasticity occur at excitatory synapses of SOM interneurons, notably anti-Hebbian LTP at BiC and OLM cell synapses (Lamsa et al., 2007), LTP at HIL cell synapses, and LTD at HIPP cell synapses (Yuan et al., 2017). These multiple types of synaptic plasticity may each supports a different function in the formation and consolidation of hippocampus-dependent memory. Therefore, it would be important to demonstrate these roles in hippocampal function using cell-specific manipulations and hippocampal learning tasks.

Another largely unresolved question is the role of the release of the endogenous peptide SOM in SOM interneuron function. Ablation of the SOM gene or depletion of SOM by cysteamine treatment impairs LTP in CA1 PCs and impedes contextual fear memory (Kluge et al., 2008). Similarly, blocking LTP at excitatory synapses of SOM interneurons decreases contextual fear memory and prevents the facilitation of SC-PC LTP by SOM interneuron synaptic plasticity (Artinian et al., 2019). These effects on contextual fear memory and on CA1 PC synaptic plasticity suggest a possible link between the peptide SOM and long-term plasticity at SOM interneuron excitatory synapses. This would be interesting to explore given that endogenous SOM release is considered to be activity-dependent.

Work on astrocyte regulation of SOM interneuron synapses focused largely on astrocyte interactions at inhibitory synapses made by SOM interneurons on PC dendrites (Matos et al., 2018). However, astrocyte interactions are largely documented at excitatory synapses onto PCs and linked to regulation of long-term plasticity at these synapses (Araque et al., 2014). Interestingly, the activity of astrocytic glutamate transporters GLT-1 and GLAST regulate mGluR1-mediated slow EPSCs in CA1 OLM cells, indicating a functional interaction of astrocytes at excitatory synapses onto SOM interneurons (Huang et al., 2004). Thus, it would be interesting to characterize further astrocyte interactions at these excitatory synapses and determine

\section{REFERENCES}

Abraham, W. C. (2008). Metaplasticity: tuning synapses and networks for plasticity. Nat. Rev. Neurosci. 9, 387-387. doi: 10.1038/nrn2356

Abraham, W. C., Jones, O. D., and Glanzman, D. L. (2019). Is plasticity of synapses the mechanism of long-term memory storage? NPJ Sci. Learn 4:9. doi: 10.1038/s41539-019-0048-y

Ali, A. B., and Thomson, A. M. (1998). Facilitating pyramid to horizontal oriens-alveus interneurone inputs: dual intracellular recordings in slices of rat hippocampus. J. Physiol. 507, 185-199. doi: 10.1111/j.1469-7793.1998.185bu.x how astrocytes may influence long-term synaptic plasticity of SOM interneurons, and consequently, hippocampal learning and memory.

Astrocytes also display functional heterogeneity, at least in terms of GABAergic-induced $\mathrm{Ca}^{2+}$ oscillation and gliotransmitter release. A single astrocyte can be modulated by distinct mechanisms (endocannabinoids and GABA) and can release at least two different gliotransmitters (ATP/adenosine and glutamate; Covelo and Araque, 2018). Given the different astrocytic modulation uncovered with SOM and other interneuron subtypes (Mariotti et al., 2018; Matos et al., 2018), it raises the question whether different subtypes of astrocytes may co-exist within a brain region. Astrocyte heterogeneity has already been reported between brain regions (Chai et al., 2017; Khakh and Deneen, 2019; Kohler et al., 2021). However, given the different firing properties of specific interneurons, do specific firing patterns govern the astrocytic responses or is it another level of modulation? These questions still need to be addressed.

Future progress on these and other questions will likely move forward our understanding of SOM interneuron synaptic plasticity and help uncover how these specific inhibitory cells contribute to hippocampal memory processes.

\section{AUTHOR CONTRIBUTIONS}

All authors contributed to the article and approved the submitted version.

\section{FUNDING}

This work and research in the laboratory of J-CL were supported by grants from the Canadian Institutes of Health Research (CIHR MOP-125985 and PJT-153311), a Research Centre grant (Centre Interdisciplinaire de Recherche sur le Cerveau et l'Apprentissage; CIRCA) from the Fonds de la Recherche du Québec-Santé (FRQS), and a Group grant from Université de Montréal (Groupe de Recherche sur le Système Nerveux Central; GRSNC). J$\mathrm{CL}$ is the recipient of the Canada Research Chair in Cellular and Molecular Neurophysiology (CRC 950-231066). AK was supported by a fellowship from the Réseau de Médecine Génétique Appliquée (Montréal, Canada).

\section{ACKNOWLEDGMENTS}

We thank Drs. Isabel Laplante, François-Xavier Michon, and Darren Clarke for discussions and help with the manuscript.

Andersson, M., Blomstrand, F., and Hanse, E. (2007). Astrocytes play a critical role in transient heterosynaptic depression in the rat hippocampal Ca1 region. J. Physiol. 585, 843-852. doi: 10.1113/jphysiol.2007. 142737

Araque, A., Carmignoto, G., Haydon, P. G., Oliet, S. H., Robitaille, R., and Volterra, A. (2014). Gliotransmitters travel in time and space. Neuron 81, 728-739. doi: 10.1016/j.neuron.2014.02.007

Araque, A., Parpura, V., Sanzgiri, R. P., and Haydon, P. G. (1999). Tripartite synapses: glia, the unacknowledged partner. Trends Neurosci. 22, 208-215. doi: $10.1016 / \mathrm{s} 0166-2236(98) 01349-6$ 
Artinian, J., and Lacaille, J.-C. (2018). Disinhibition in learning and memory circuits: new vistas for somatostatin interneurons and long-term synaptic plasticity. Brain Res. Bull. 141, 20-26. doi: 10.1016/j.brainresbull.2017. 11.012

Artinian, J., Jordan, A., Khlaifia, A., Honore, E., La Fontaine, A., Racine, A. S., et al. (2019). Regulation of hippocampal memory by mtorcl in somatostatin interneurons. J. Neurosci. 39, 8439-8456. doi: 10.1523/JNEUROSCI.072819.2019

Auld, D. S., Kornecook, T. J., Bastianetto, S., and Quirion, R. (2002). Alzheimer's disease and the basal forebrain cholinergic system: relations to $\beta$-amyloid peptides, cognition and treatment strategies. Prog. Neurobiol. 68, 209-245. doi: 10.1016/s0301-0082(02)00079-5

Bazargani, N., and Attwell, D. (2016). Astrocyte calcium signaling: the third wave. Nat. Neurosci. 19, 182-189. doi: 10.1038/nn.4201

Bear, M. F. (1995). Mechanism for a sliding synaptic modification threshold. Neuron 15, 1-4. doi: 10.1016/0896-6273(95)90056-x

Bittner, K. C., Grienberger, C., Vaidya, S. P., Milstein, A. D., Macklin, J. J., Suh, J., et al. (2015). Conjunctive input processing drives feature selectivity in hippocampal Ca1 neurons. Nat. Neurosci. 18, 1133-1142. doi: 10.1038/nn.4062

Bittner, K. C., Milstein, A. D., Grienberger, C., Romani, S., and Magee, J. C. (2017). Behavioral time scale synaptic plasticity underlies Cal place fields. Science 357, 1033-1036. doi: 10.1126/science.aan3846

Blasco-Ibáñez, J. M., and Freund, T. F. (1995). Synaptic input of horizontal interneurons in stratum oriens of the hippocampal Cal subfield: Structural basis of feed-back activation. Eur. J. Neurosci. 7, 2170-2180. doi: 10.1111/j. 1460-9568.1995.tb00638.x

Boddum, K., Jensen, T. P., Magloire, V., Kristiansen, U., Rusakov, D. A., Pavlov, I., et al. (2016). Astrocytic gaba transporter activity modulates excitatory neurotransmission. Nat. Commun. 7:13572. doi: 10.1038/ncomms13572

Booker, S. A., and Vida, I. (2018). Morphological diversity and connectivity of hippocampal interneurons. Cell Tissue Res. 373, 619-641. doi: 10.1007/s00441018-2882-2

Booker, S. A., Harada, H., Elgueta, C., Bank, J., Bartos, M., Kulik, A., et al. (2020). Presynaptic gabab receptors functionally uncouple somatostatin interneurons from the active hippocampal network. eLife 9:e51156. doi: 10.7554/eLife. 51156

Booker, S. A., Loreth, D., Gee, A. L., Watanabe, M., Kind, P. C., Wyllie, D. J. A., et al. (2018). Postsynaptic gababrs inhibit l-type calcium channels and abolish long-term potentiation in hippocampal somatostatin interneurons. Cell Rep. 22, 36-43. doi: 10.1016/j.celrep.2017.12.021

Borden, L. A., and Caplan, M. J. (1996). GABA transporter heterogeneity: pharmacology and cellular localization. Neurochem. Int. 29, 335-356. doi: 10.1016/0197-0186(95)00158-1

Brazeau, P., Vale, W., Burgus, R., Ling, N., Butcher, M., Rivier, J., et al. (1973). Hypothalamic polypeptide that inhibits the secretion of immunoreactive pituitary growth hormone. Science 179, 77-79. doi: 10.1126/science.179. 4068.77

Buhl, E. H., Szilágyi, T., Halasy, K., and Somogyi, P. (1996). Physiological properties of anatomically identified basket and bistratified cells in the Cal area of the rat hippocampus in vitro. Hippocampus 6, 294-305. doi: 10.1002/(SICI)1098-1063(1996)6:3<294::AID-HIPO7>3.0.CO;2-N

Buzsáki, G. (2002). Theta oscillations in the hippocampus. Neuron 33, 325-340. doi: 10.1016/s0896-6273(02)00586-x

Buzsaki, G., and Eidelberg, E. (1982). Direct afferent excitation and long-term potentiation of hippocampal interneurons. J. Neurophysiol. 48, 597-607. doi: 10.1152/jn.1982.48.3.597

Buzsaki, G., Horvath, Z., Urioste, R., Hetke, J., and Wise, K. (1992). Highfrequency network oscillation in the hippocampus. Science 256, 1025-1027. doi: 10.1126/science. 1589772

Cammalleri, M., Bagnoli, P., and Bigiani, A. (2019). Molecular and cellular mechanisms uderlying somatostatin-based signaling in two model neural networks: the retina and the hippocampus. Int. J. Mol. Sci. 20:2506. doi: 10.3390/ijms20102506

Caporale, N., and Dan, Y. (2008). Spike timing-dependent plasticity: a hebbian learning rule. Annu. Rev. Neurosci. 31, 25-46. doi: 10.1146/annurev.neuro.31. 060407.125639

Chai, H., Diaz-Castro, B., Shigetomi, E., Monte, E., Octeau, J. C., Yu, X., et al. (2017). Neural circuit-specialized astrocytes: transcriptomic, proteomic, morphological and functional evidence. Neuron 95, 531.e9.-549.e9. doi: 10.1016/j.neuron.2017.06.029

Chevaleyre, V., Takahashi, K. A., and Castillo, P. E. (2006). Endocannabinoidmediated synaptic plasticity in the cns. Annu. Rev. Neurosci. 29, 37-76. doi: 10.1146/annurev.neuro.29.051605.112834

Chittajallu, R., Craig, M. T., McFarland, A., Yuan, X., Gerfen, S., Tricoire, L., et al. (2013). Dual origins of functionally distinct O-LM interneurons revealed by differential 5-HT3AR expression. Nat. Neurosci. 16, 1598-1607. doi: $10.1038 / \mathrm{nn} .3538$

Chung, H., Park, K., Jang, H. J., Kohl, M. M., and Kwag, J. (2020). Dissociation of somatostatin and parvalbumin interneurons circuit dysfunctions underlying hippocampal theta and gamma oscillations impaired by amyloid beta oligomers in vivo. Brain Struct. Funct. 225, 935-954. doi: 10.1007/s00429-02002044-3

Citri, A., and Malenka, R. C. (2008). Synaptic plasticity: multiple forms, functions and mechanisms. Neuropsychopharmacology 33, 18-41. doi: 10.1038/sj.npp. 1301559

Costa-Mattioli, M., Gobert, D., Stern, E., Gamache, K., Colina, R., Cuello, C., et al. (2007). Eif $2 \alpha$ phosphorylation bidirectionally regulates the switch from shortto long-term synaptic plasticity and memory. Cell 129, 195-206. doi: 10.1016/j. cell.2007.01.050

Covelo, A., and Araque, A. (2018). Neuronal activity determines distinct gliotransmitter release from a single astrocyte. eLife 7:e32237. doi: 10.7554/eLife.32237

Croce, A., Pelletier, J. G., Tartas, M., and Lacaille, J. C. (2010). Afferent-specific properties of interneuron synapses underlie selective long-term regulation of feedback inhibitory circuits in Cal hippocampus. J. Physiol. 588, 2091-2107. doi: 10.1113/jphysiol.2010.189316

Csaba, Z., and Dournaud, P. (2001). Cellular biology of somatostatin receptors. Neuropeptides 35, 1-23. doi: 10.1054/npep.2001.0848

Davies, C., Mann, D., Sumpter, P., and Yates, P. (1987). A quantitative morphometric analysis of the neuronal and synaptic content of the frontal and temporal cortex in patients with Alzheimers disease. J. Neurol. Sci. 78, 151-164. doi: $10.1016 / 0022-510 x(87) 90057-8$

Davies, C. H., Starkey, S. J., Pozza, M. F., and Collingridge, G. L. (1991). GABA autoreceptors regulate the induction of LTP. Nature 349, 609-611. doi: $10.1038 / 349609 \mathrm{a} 0$

Davies, P., Katzman, R., and Terry, R. D. (1980). Reduced somatostatin-like immunoreactivity in cerebral cortex from cases of Alzheimer disease and Alzheimer senile dementa. Nature 288, 279-280. doi: 10.1038/288 279a0

De Bundel, D., Aourz, N., Kiagiadaki, F., Clinckers, R., Hoyer, D., Kastellakis, A., et al. (2010). Hippocampal SST1 receptors are autoreceptors and do not affect seizures in rats. NeuroReport 21, 254-258. doi: 10.1097/WNR. 0b013e3283353a64

Degro, C. E., Kulik, A., Booker, S. A., and Vida, I. (2015). Compartmental distribution of GABAB receptor-mediated currents along the somatodendritic axis of hippocampal principal cells. Front. Synaptic Neurosci. 7:6 doi: 10.3389/fnsyn.2015.00006

Delfs, J., and Dichter, M. (1983). Effects of somatostatin on mammalian cortical neurons in culture: physiological actions and unusual dose response characteristics. J. Neurosci. 3, 1176-1188. doi: 10.1523/JNEUROSCI.03-0601176.1983

Ding, S., Wang, T., Cui, W., and Haydon, P. G. (2009). Photothrombosis ischemia stimulates a sustained astrocytic calcium signaling in vivo. Glia 57, 767-776. doi: 10.1002/glia.20804

Durkee, C. A., and Araque, A. (2019). Diversity and specificity of astrocyte-neuron communication. Neuroscience 396, 73-78. doi: 10.1016/j.neuroscience.2018. 11.010

Dutar, P., and Nicoll, R. A. (1988). A physiological role for gabab receptors in the central nervous system. Nature 332, 156-158. doi: 10.1038/332156a0

Egawa, K., Yamada, J., Furukawa, T., Yanagawa, Y., and Fukuda, A. (2013). Choride homeodynamics in gap junction-coupled astrocytic networks on activation of gabaergic synapses. J. Physiol. 591, 3901-3917. doi: 10.1113/jphysiol.2013.257162

Elder, G. A., Gama Sosa, M. A., and De Gasperi, R. (2010). Transgenic mouse models of Alzheimers disease. Mt. Sinai. J. Med. 77, 69-81. doi: 10.1002/msj. 20159 
Elfant, D., Pál, B. Z., Emptage, N., and Capogna, M. (2008). Specific inhibitory synapses shift the balance from feedforward to feedback inhibition of hippocampal Ca1 pyramidal cells. Eur. J. Neurosci. 27, 104-113. doi: 10.1111/j. 1460-9568.2007.06001.x

Eyre, M. D., and Bartos, M. (2019). Somatostatin-expressing interneurons form axonal projections to the contralateral hippocampus. Front. Neural Circuits 13:56. doi: $10.3389 /$ fncir.2019.00056

Feldman, D. E. (2012). The spike-timing dependence of plasticity. Neuron 75, 556-571. doi: 10.1016/j.neuron.2012.08.001

Ferraguti, F., Cobden, P., Pollard, M., Cope, D., Shigemoto, R., Watanabe, M., et al. (2004). Immunolocalization of metabotropic glutamate receptor $1 \alpha$ (mglur $1 \alpha)$ in distinct classes of interneuron in the Cal region of the rat hippocampus. Hippocampus 14, 193-215. doi: 10.1002/hipo.10163

Freund, T. F., and Buzsáki, G. (1996). Interneurons of the hippocampus. Hippocampus 6, 347-470. doi: 10.1002/(SICI)1098-1063(1996)6:4<347::AIDHIPO1>3.0.CO;2-I

Friend, L. N., Williamson, R. C., Merrill, C. B., Newton, S. T., Christensen, M. T., Petersen, J., et al. (2019). Hippocampal stratum oriens somatostatinpositive cells undergo cbl-dependent long-term potentiation and express endocannabinoid biosynthetic enzymes. Molecules 24:1306. doi: 10.3390/molecules 24071306

Gastambide, F., Viollet, C., Lepousez, G., Epelbaum, J., and Guillou, J.-L. (2008). Hippocampal sstr4 somatostatin receptors control the selection of memory strategies. Psychopharmacology 202:153. doi: 10.1007/s00213-008-1204-x

Goldin, M., Epsztein, J., Jorquera, I., Represa, A., Ben-Ari, Y., Crépel, V., et al. (2007). Synaptic kainate receptors tune oriens-lacunosum moleculare interneurons to operate at theta frequency. J. Neurosci. 27, 9560-9572. doi: 10.1523/JNEUROSCI.1237-07.2007

Goshen, I. (2014). The optogenetic revolution in memory research. Trends Neurosci. 37, 511-522. doi: 10.1016/j.tins.2014.06.002

Graeber, M., Kösel, S., Egensperger, R., Banati, R., Müller, U., Bise, K., et al. (1997). Rediscovery of the case described by alois Alzheimer in 1911: historical, histological and molecular genetic analysis. Neurogenetics 1, 73-80. doi: $10.1007 / \mathrm{s} 100480050011$

Grienberger, C., Milstein, A. D., Bittner, K. C., Romani, S., and Magee, J. C. (2017). Inhibitory suppression of heterogeneously tuned excitation enhances spatial coding in Ca1 place cells. Nat. Neurosci. 20, 417-426. doi: 10.1038/nn. 4486

Guillou, J.-L., Micheau, J., and Jaffard, R. (1993). Effects of intrahippocampal injections of somatostatin and cysteamine on spatial discrimination learning in mice. Psychobiology 21, 265-271. doi: 10.3758/BF03327144

Gulyas, A. I., Hajos, N., Katona, I., and Freund, T. F. (2003). Interneurons are the local targets of hippocampal inhibitory cells which project to the medial septum. Eur. J. Neurosci. 17, 1861-1872. doi: 10.1046/j.1460-9568.2003. 02630.x

Günther, T., Tulipano, G., Dournaud, P., Bousquet, C., Csaba, Z., Kreienkamp, HJ., et al. (2018). International union of basic and clinical pharmacology. Cv. Somatostatin receptors: structure, function, ligands and new nomenclature. Pharmacol. Rev. 70, 763-835. doi: 10.1124/pr.117.015388

Halasy, K., Buhl, E. H., Lörinczi, Z., Tamás, G., and Somogyi, P. (1996). Synaptic target selectivity and input of gabaergic basket and bistratified interneurons in the Cal area of the rat hippocampus. Hippocampus 6, 306-329. doi: 10.1002/(SICI)1098-1063(1996)6:3<306::AID-HIPO8>3.0.CO;2-K

Han, Z. S., Buhl, E. H., Lorinczi, Z., and Somogyi, P. (1993). A high degree of spatial selectivity in the axonal and dendritic domains of physiologically identified local-circuit neurons in the dentate gyrus of the rat hippocampus. Eur. J. Neurosci. 5, 395-410. doi: 10.1111/j.1460-9568.1993.tb00507.x

Harvey, C. D., Collman, F., Dombeck, D. A., and Tank, D. W. (2009). Intracellular dynamics of hippocampal place cells during virtual navigation. Nature 461, 941-946. doi: 10.1038/nature08499

Haustein, M. D., Kracun, S., Lu, X. H., Shih, T., Jackson-Weaver, O., Tong, X., et al. (2014). Conditions and constraints for astrocyte calcium signaling in the hippocampal mossy fiber pathway. Neuron 82, 413-429. doi: 10.1016/j.neuron. 2014.02.041

Hosp, J. A., Struber, M., Yanagawa, Y., Obata, K., Vida, I., Jonas, P., et al. (2014). Morpho-physiological criteria divide dentate gyrus interneurons into classes. Hippocampus 24, 189-203. doi: 10.1002/hipo.22214
Houser, C. R. (2007). Interneurons of the dentate gyrus: an overview of cell types, terminal fields and neurochemical identity. Prog. Brain Res. 163, 217-232. doi: 10.1016/S0079-6123(07)63013-1

Hou, Z. H., and Yu, X. (2013). Activity-regulated somatostatin expression reduces dendritic spine density and lowers excitatory synaptic transmission via postsynaptic somatostatin reptor 4. J. Biol. Chem. 288, 2501-2509. doi: $10.1074 /$ jbc.M112.419051

Huang, Y., and Mucke, L. (2012). Alzheimer mechanisms and therapeutic strategies. Cell 148, 1204-1222. doi: 10.1016/j.cell.2012.02.040

Huang, Y. H., Sinha, S. R., Tanaka, K., Rothstein, J. D., and Bergles, D. E. (2004). Astrocyte glutamate transporters regulate metabotropic glutamate receptormediated excitation of hippocampal interneurons. J. Neurosci. 24, 4551-4559. doi: 10.1523/JNEUROSCI.5217-03.2004

Ishibashi, M., Egawa, K., and Fukuda, A. (2019). Diverse actions of astrocytes in gabaergic signaling. Int. J. Mol. Sci. 20:2964. doi: 10.3390/ijms20122964

Jinno, S., Klausberger, T., Marton, L. F., Dalezios, Y., Roberts, J. D., Fuentealba, P., et al. (2007). Neuronal diversity in gabaergic long-range projections from the hippocampus. J. Neurosci. 27, 8790-8804. doi: 10.1523/JNEUROSCI.184707.2007

Josselyn, S. A., and Frankland, P. W. (2018). Memory allocation: mechanisms and function. Annu. Rev. Neurosci. 41, 389-413. doi: 10.1146/annurev-neuro080317-061956

Kandel, E. R. (2001). The molecular biology of memory storage: a dialogue between genes and synapses. Science 294, 1030-1038. doi: 10.1126/science. 1067020

Kandel, E. R., Dudai, Y., and Mayford, M. R. (2014). The molecular and systems biology of memory. Cell 157, 163-186. doi: 10.1016/j.cell.2014.03.001

Kang, J., Jiang, L., Goldman, S. A., and Nedergaard, M. (1998). Astrocyte-mediated potentiation of inhibitory synaptic transmission. Nat. Neurosci. 1, 683-692. doi: $10.1038 / 3684$

Katona, I., Acsády, L., and Freund, T. F. (1999). Postsynaptic targets of somatostatin-immunoreactive interneurons in the rat hippocampus. Neuroscience 88, 37-55. doi: 10.1016/s0306-4522(98)00302-9

Katona, L., Lapray, D., Viney, T. J., Oulhaj, A., Borhegyi, Z., Micklem, B. R., et al. (2014). Sleep and movement differentiates actions of two types of somatostatinexpressing gabaergic interneuron in rat hippocampus. Neuron 82, 872-886. doi: 10.1016/j.neuron.2014.04.007

Katona, L., Micklem, B., Borhegyi, Z., Swiejkowski, D. A., Valenti, O., Viney, T. J., et al. (2017). Behavior-dependent activity patterns of gabaergic long-range projecting neurons in the rat hippocampus. Hippocampus 27, 359-377. doi: 10.1002/hipo.22696

Kepecs, A., and Fishell, G. (2014). Interneuron cell types are fit to function. Nature 505, 318-326. doi: 10.1038/nature12983

Khakh, B. S., and Deneen, B. (2019). The emerging nature of astrocyte diversity. Annu. Rev. Neurosci. 42, 187-207. doi: 10.1146/annurev-neuro-070918-050443

Klausberger, T., and Somogyi, P. (2008). Neuronal diversity and temporal dynamics: the unity of hippocampal circuit operations. Science 321, 53-57. doi: 10.1126/science.1149381

Klausberger, T., Magill, P. J., Márton, L. F., Roberts, J. D. B., Cobden, P. M., Buzsáki, G., et al. (2003). Brain-state- and cell-typespecific firing of hippocampal interneurons in vivo. Nature 421, 844-848. doi: 10.1038/nature01374

Klausberger, T., Marton, L. F., Baude, A., Roberts, J. D., Magill, P. J., and Somogyi, P. (2004). Spike timing of dendrite-targeting bistratified cells during hippocampal network oscillations in vivo. Nat. Neurosci. 7, 41-47. doi: $10.1038 / \mathrm{nn} 1159$

Kluge, C., Stoppel, C., Szinyei, C., Stork, O., and Pape, H. C. (2008). Role of the somatostatin system in contextual fear memory and hippocampal plasticity. Learn Mem. 3, 252-260. doi: 10.1101/lm.793008

Koffie, R. M., Meyer-Luehmann, M., Hashimoto, T., Adams, K. W., Mielke, M. L., Garcia-Alloza, M., et al. (2009). Oligomeric amyloid $\beta$ associates with postsynaptic densities and correlates with excitatory synapse loss near senile plaques. Proc. Natl. Acad. Sci. U S A 106, 4012-4017. doi: 10.1073/pnas. 0811698106

Kohler, S., Winkler, U., and Hirrlinger, J. (2021). Heterogeneity of astrocytes in gray and white matter. Neurochem. Res. 46, 3-14. doi: 10.1007/s11064-01902926-x 
Kougioumoutzakis, A., Pelletier, J. G., Laplante, I., Khlaifia, A., and Lacaille, J. C. (2020). Trpcl mediates slow excitatory synaptic transmission in hippocampal oriens/alveus interneurons. Mol. Brain 13:12. doi: 10.1186/s13041-020-0558-9

Krulich, L., Dhariwal, A. P. S., and McCann, S. M. (1968). Stimulatory and inhibitory effects of purified hypothalamic extracts on growth hormone release from rat pituitary in vitro1. Endocrinology 83, 783-790. doi: 10.1210/endo-834-783

Kullmann, D. M., and Lamsa, K. P. (2007). Long-term synaptic plasticity in hippocampal interneurons. Nat. Rev. Neurosci. 8, 687-699. doi: $10.1038 / \mathrm{nrn} 2207$

Kullmann, D. M., and Lamsa, K. P. (2011). Interneurons go plastic. Neuropharmacology 60:711. doi: 10.1016/j.neuropharm.2011.02.001

Lacaille, J. C., and Williams, S. (1990). Membrane properties of interneurons in stratum oriens-alveus of the Cal region of rat hippocampus in vitro. Neuroscience 36, 349-359. doi: 10.1016/0306-4522(90)90431-3

Lacaille, J. C., Mueller, A. L., Kunkel, D. D., and Schwartzkroin, P. A. (1987). Local circuit interactions between oriens/alveus interneurons and $\mathrm{Ca} 1$ pyramidal cells in hippocampal slices: electrophysiology and morphology. J. Neurosci. 7, 1979-1993. doi: 10.1523/JNEUROSCI.07-07-01979.1987

Laezza, F., and Dingledine, R. (2004). Voltage-controlled plasticity at glur2deficient synapses onto 1319 hippocampal interneurons. J. Neurophysiol. 92, 3575-3581. doi: 10.1152/jn.00425.2004

Laezza, F., Doherty, J. J., and Dingledine, R. (1999). Long-term depression in hippocampal interneurons: Joint requirement for pre- and postsynaptic events. Science 285, 1411-1414. doi: 10.1126/science.285.5432.1411

Lamirault, L., Guillou, J. L., Micheau, J., and Jaffard, R. (2001). Intrahippocampal injections of somatostatin dissociate acquisition from the flexible use of place responses. Eur. J. Neurosci. 14, 567-570. doi: 10.1046/j.0953-816x.2001. 01672.x

Lamsa, K., Heeroma, J. H., and Kullmann, D. M. (2005). Hebbian ltp in feed-forward inhibitory interneurons and the temporal fidelity of input discrimination. Nat. Neurosci. 8, 916-924. doi: 10.1038/nn1486

Lamsa, K. P., Heeroma, J. H., Somogyi, P., Rusakov, D. A., and Kullmann, D. M. (2007). Anti-hebbian long-term potentiation in the hippocampal feedback inhibitory circuit. Science 315, 1262-1266. doi: 10.1126/science.1137450

Lapointe, V., Morin, F., Ratte, S., Croce, A., Conquet, F., and Lacaille, J. C. (2004). Synapse-specific mglur1-dependent long-term potentiation in interneurones regulates mouse hippocampal inhibition. J. Physiol. 555, 125-135. doi: 10.1113/jphysiol.2003.053603

Larimer, P., and Strowbridge, B. W. (2008). Nonrandom local circuits in the dentate gyrus. J. Neurosci. 28, 12212-12223. doi: 10.1523/JNEUROSCI.361208.2008

Le Vasseur, M., Ran, I., and Lacaille, J. C. (2008). Selective induction of metabotropic glutamate receptor 1 - and metabotropic glutamate receptor 5 -dependent chemical long-term potentiation at oriens/alveus interneuron synapses of mouse hippocampus. Neuroscience 151, 28-42. doi: 10.1016/j. neuroscience.2007.09.071

Leao, R. N., Mikulovic, S., Leao, K. E., Munguba, H., Gezelius, H., Enjin, A., et al. (2012). Olm interneurons differentially modulate ca3 and entorhinal inputs to hippocampal Ca1 neurons. Nat. Neurosci. 15, 1524-1530. doi: 10.1038/nn.3235

Lee, D., Lin, B. J., and Lee, A. K. (2012). Hippocampal place fields emerge upon single-cell manipulation of excitability during behavior. Science 337, 849-853. doi: 10.1126/science.1221489

Lee, S., Yoon, B.-E., Berglund, K., Oh, S.-J., Park, H., Shin, H.-S., et al. (2010). Channel-mediated tonic gaba release from glia. Science 330, 790-796. doi: 10.1126/science.1184334

Lia, A., Zonta, M., Requie, L. M., and Carmignoto, G. (2019). Dynamic interactions between gabaergic and astrocytic networks. Neurosci. Lett. 689, 14-20. doi: 10.1016/j.neulet.2018.06.026

Liguz-Lecznar, M., Urban-Ciecko, J., and Kossut, M. (2016). Somatostatin and somatostatin-containing neurons in shaping neuronal activity and plasticity. Front. Neural Circuits 10:48. doi: 10.3389/fncir.2016.00048

Liu, Q. S., Xu, Q., Arcuino, G., Kang, J., and Nedergaard, M. (2004). Astrocytemediated activation of neuronal kainate receptors. Proc. Natl. Acad. Sci. US A 101, 3172-3177. doi: 10.1073/pnas.0306731101

Losi, G., Mariotti, L., and Carmignoto, G. (2014). Gabaergic interneuron to astrocyte signaling: a neglected form of cell communication in the brain. Philos. Trans. R. Soc. Lond. B Biol. Sci. 369:20130609. doi: 10.1098/rstb.2013.0609
Lovett-Barron, M., Kaifosh, P., Kheirbek, M. A., Danielson, N., Zaremba, J. D., Reardon, T. R., et al. (2014). Dendritic inhibition in the hippocampus supports fear learning. Science 343, 857-863. doi: 10.1126/science.1247485

Lovett-Barron, M., Turi, G. F., Kaifosh, P., Lee, P. H., Bolze, F., Sun, X. H., et al. (2012). Regulation of neuronal input transformations by tunable dendritic inhibition. Nat. Neurosci. 15, 423-430. doi: 10.1038/nn.3024

Luján, R., Nusser, Z., Roberts, J. D. B., Shigemoto, R., and Somogyi, P. (1996). Perisynaptic location of metabotropic glutamate receptors mglur1 and mglur5 on dendrites and dendritic spines in the rat hippocampus. Eur. J. Neurosci. 8, 1488-1500. doi: 10.1038/s41467-02122435-2

Maccaferri, G., and McBain, C. J. (1996). Long-term potentiation in distinct subtypes of hippocampal nonpyramidal neurons. J. Neurosci. 16, 5334-5343. doi: 10.1523/JNEUROSCI.16-17-05334.1996

Maccaferri, G., David, J., Roberts, B., Szucs, P., Cottingham, C. A., and Somogyi, P. (2000). Cell surface domain specific postsynaptic currents evoked by identified gabaergic neurones in rat hippocampus in vitro. J. Physiol. 524, 91-116. doi: 10.1111/j.1469-7793.2000.t01-3-00091.x

Magee, J. C., and Grienberger, C. (2020). Synaptic plasticity forms and functions. Annu. Rev. Neurosci. 43, 95-117. doi: 10.1146/annurev-neuro-090919-022842

Malenka, R. C., and Bear, M. F. (2004). Ltp and ltd: An embarrassment of riches. Neuron 44, 5-21. doi: 10.1016/j.neuron.2004.09.012

Mariotti, L., Losi, G., Lia, A., Melone, M., Chiavegato, A., Gómez-Gonzalo, M., et al. (2018). Interneuron-specific signaling evokes distinctive somatostatinmediated responses in adult cortical astrocytes. Nat. Commun. 9:82. doi: 10.1038/s41467-017-02642-6

Mariotti, L., Losi, G., Sessolo, M., Marcon, I., and Carmignoto, G. (2016). The inhibitory neurotransmitter gaba evokes long-lasting $\mathrm{ca}(2+)$ oscillations in cortical astrocytes. Glia 64, 363-373. doi: 10.1002/glia. 22933

Masliah, E., Mallory, M., Alford, M., DeTeresa, R., Hansen, L., McKeel, D., et al. (2001). Altered expression of synaptic proteins occurs early during progression of Alzheimer's disease. Neurology 56, 127-129. doi: 10.1212/wnl. 56.1.127

Matos, M., Bosson, A., Riebe, I., Reynell, C., Vallée, J., Laplante, I., et al. (2018). Astrocytes detect and upregulate transmission at inhibitory synapses of somatostatin interneurons onto pyramidal cells. Nat. commun. 9, 1-15. doi: 10.1038/s41467-018-06731-y

McBain, C. J., Freund, T. F., and Mody, I. (1999). Glutamatergic synapses onto hippocampal interneurons: Precision timing without lasting plasticity. Trends Neurosci. 22, 228-235. doi: 10.1016/s0166-2236(98)01347-2

Mederos, S., and Perea, G. (2019). Gabaergic-astrocyte signaling: a refinement of inhibitory brain networks. Glia 67, 1842-1851. doi: 10.1002/glia. 23644

Melzer, S., Michael, M., Caputi, A., Eliava, M., Fuchs, E. C., Whittington, M. A., et al. (2012). Long-range-projecting gabaergic neurons modulate inhibition in hippocampus and entorhinal cortex. Science 335, 1506-1510. doi: $10.1126 /$ science. 1217139

Mikulovic, S., Restrepo, C. E., Hilscher, M. M., Kullander, K., and Leao, R. (2015). Novel markers for olm interneurons in the hippocampus. Front. Cell. Neurosci. 9:201. doi: 10.3389/fncel.2015.00201

Mondragon-Rodriguez, S., Salas-Gallardo, A., Gonzalez-Pereyra, P., Macias, M., Ordaz, B., Pena-Ortega, F., et al. (2018). Phosphorylation of tau protein correlates with changes in hippocampal theta oscillations and reduces hippocampal excitability in Alzheimers model. J. Biol. Chem. 293, 8462-8472. doi: 10.1074/jbc.RA117.001187

Morris, R. G. (2003). Long-term potentiation and memory. Philos. Trans. R. Soc. Lond. B Biol. Sci. 358, 643-647. doi: 10.1098/rstb.2002.1230

Morris, R. G., Anderson, E., Lynch, G. S., and Baudry, M. (1986). Selective impairment of learning and blockade of long-term potentiation by an n-methyl-d-aspartate receptor antagonist, ap5. Nature 319, 774-776. doi: $10.1038 / 319774 \mathrm{a} 0$

Mott, D. D., and Lewis, D. V. (1991). Facilitation of the induction of long-term potentiation by gabab receptors. Science 252, 1718-1720. doi: 10.1126/science. 1675489

Mucke, L., and Selkoe, D. J. (2012). Neurotoxicity of amyloid beta-protein: Synaptic and network dysfunction. Cold Spring Harb. Perspect. Med. 2:a006338. doi: $10.1101 /$ cshperspect.a006338 
Muller, C., and Remy, S. (2014). Dendritic inhibition mediated by o-lm and bistratified interneurons in the hippocampus. Front. Synaptic Neurosci. 6:23. doi: 10.3389/fnsyn.2014.00023

Nilsson, M., Eriksson, P. S., Rönnbäck, L., and Hansson, E. (1993). GABA induces $\mathrm{ca}^{2+}$ transients in astrocytes. Neuroscience 54, 605-614. doi: 10.1016/03064522(93)90232-5

O'Keefe, J., and Dostrovsky, J. (1971). The hippocampus as a spatial map. Preliminary evidence from unit activity in the freely-moving rat. Brain Res. 34, 171-175. doi: 10.1016/0006-8993(71)90358-1

O'Keefe, J., and Nadel, L. (1978). The Hippocampus as a Cognitive Map. Oxford: Clarendon Press.

Oliva, A. A. Jr., Jiang, M., Lam, T., Smith, K. L., and Swann, J. W. (2000). Novel hippocampal interneuronal subtypes identified using transgenic mice that express green fluorescent protein in gabaergic interneurons. J. Neurosci. 20, 3354-3368. doi: 10.1523/JNEUROSCI.20-09-03354.2000

Olpe, H.-R., Balcar, V. J., Bittiger, H., Rink, H., and Sieber, P. (1980). Central actions of somatostatin. Eur. J. Pharmacol. 63, 127-133. doi: 10.1016/00142999(80)90436-7

Palop, J. J., and Mucke, L. (2016). Network abnormalities and interneuron dysfunction in Alzheimer disease. Nat. Rev. Neurosci. 17, 777-792. doi: $10.1038 / \mathrm{nrn} .2016 .141$

Pelkey, K. A., Chittajallu, R., Craig, M. T., Tricoire, L., Wester, J. C., and McBain, C. J. (2017). Hippocampal gabaergic inhibitory interneurons. Physiol. Rev. 97, 1619-1747. doi: 10.1152/physrev.00007.2017

Pelletier, J. G., and Lacaille, J. C. (2008). Long-term synaptic plasticity in hippocampal feedback inhibitory networks. Prog. Brain Res. 169, 241-250. doi: 10.1016/S0079-6123(07)00014-3

Perea, G., Gómez, R., Mederos, S., Covelo, A., Ballesteros, J. J., Schlosser, L., et al. (2016). Activity-dependent switch of gabaergic inhibition into glutamatergic excitation in astrocyte-neuron networks. eLife 5:e20362. doi: 10.7554/eLife. 20362

Perez, S. E., Dar, S., Ikonomovic, M. D., DeKosky, S. T., and Mufson, E. J. (2007). Cholinergic forebrain degeneration in the appswe/ps1 $1 \mathrm{e} 9$ transgenic mouse. Neurobiol. Dis. 28, 3-15. doi: 10.1016/j.nbd.2007.06.015

Perez, Y., Morin, F., and Lacaille, J. C. (2001). A hebbian form of long-term potentiation dependent on mglurla in hippocampal inhibitory interneurons. Proc. Natl. Acad. Sci. U S A 98, 9401-9406. doi: 10.1073/pnas.1614 93498

Pike, F. G., Goddard, R. S., Suckling, J. M., Ganter, P., Kasthuri, N., and Paulsen, O. (2000). Distinct frequency preferences of different types of rat hippocampal neurones in response to oscillatory input currents. J. Physiol. 529, 205-213. doi: 10.1111/j.1469-7793.2000.00205.x

Pittman, Q. J., and Siggins, G. R. (1981). Somatostatin hyperpolarizes hippocampal pyramidal cells in vitro. Brain Res. 221, 402-408. doi: 10.1016/00068993(81)90791-5

Pouille, F., and Scanziani, M. (2004). Routing of spike series by dynamic circuits in the hippocampus. Nature 429, 717-723. doi: 10.1038/nature 02615

Prévôt, T. D., Gastambide, F., Viollet, C., Henkous, N., Martel, G., Epelbaum, J., et al. (2017). Roles of hippocampal somatostatin receptor subtypes in stress response and emotionality. Neuropsychopharmacology 42, 1647-1656. doi: $10.1038 / \mathrm{npp} .2016 .281$

Ramos, B., Baglietto-Vargas, D., del Rio, J. C., Moreno-Gonzalez, I., SantaMaria, C., Jimenez, S., et al. (2006). Early neuropathology of somatostatin/npy gabaergic cells in the hippocampus of a ps1xapp transgenic model of Alzheimers disease. Neurobiol. Aging 27, 1658-1672. doi: 10.1016/j. neurobiolaging.2005.09.022

Ran, I., Laplante, I., and Lacaille, J. C. (2012). Creb-dependent transcriptional control and quantal changes in persistent long-term potentiation in hippocampal interneurons. J. Neurosci. 32, 6335-6350. doi: 10.1523/JNEUROSCI.5463-11.2012

Ran, I., Laplante, I., Bourgeois, C., Pepin, J., Lacaille, P., Costa-Mattioli, M., et al. (2009). Persistent transcription- and translation-dependent long-term potentiation induced by mglur1 in hippocampal interneurons. J. Neurosci. 29, 5605-5615. doi: 10.1523/JNEUROSCI.5355-08.2009

Ribak, C. E., Tong, W. M., and Brecha, N. C. (1996). GABA plasma membrane transporters, gat-1 and gat-3, display different distributions in the rat hippocampus. J. Comp. Neurol. 367, 595-606. doi: 10.1002/(SICI)10969861(19960415)367:4<595::AID-CNE9>3.0.CO;2-\#

Royer, S., Zemelman, B. V., Losonczy, A., Kim, J., Chance, F., Magee, J. C., et al. (2012). Control of timing, rate and bursts of hippocampal place cells by dendritic and somatic inhibition. Nat. Neurosci. 15, 769-775. doi: 10.1038/ nn.3077

Sanchez-Mejias, E., Nunez-Diaz, C., Sanchez-Varo, R., Gomez-Arboledas, A., Garcia-Leon, J. A., Fernandez-Valenzuela, J. J., et al. (2020). Distinct diseasesensitive gabaergic neurons in the perirhinal cortex of Alzheimers mice and patients. Brain Pathol. 30, 345-363. doi: 10.1111/bpa.12785

Sandoval, K., Umbaugh, D., House, A., Crider, A., and Witt, K. (2019). Somatostatin receptor subtype-4 regulates mrna expression of amyloid-beta degrading enzymes and microglia mediators of phagocytosis in brains of 3xtg-ad mice. Neurochem. Res. 44, 2670-2680. doi: 10.1007/s11064-01902890-6

Savanthrapadian, S., Meyer, T., Elgueta, C., Booker, S. A., Vida, I., and Bartos, M. (2014). Synaptic properties of som- and cck-expressing cells in dentate gyrus interneuron networks. J. Neurosci. 34, 8197-8209. doi: 10.1523/JNEUROSCI. 5433-13.2014

Scharfman, H. E., and Schwartzkroin, P. A. (1988). Further studies of the effects of somatostatin and related peptides in area Cal of rabbit hippocampus. Cell Mol. Biol. 8, 411-429. doi: 10.1007/BF00711226

Scharfman, H. E., and Schwartzkroin, P. A. (1989). Selective depression of gaba-mediated ipsps by somatostatin in area Cal of rabbit hippocampal slices. Brain Res. 493, 205-211. doi: 10.1016/0006-8993(89)91155-4

Schettini, G. (1991). Brain somatostatin: receptor-coupled transducing mechanisms and role in cognitive functions. Pharmacol. Res. 23, 203-215. doi: 10.1016/s1043-6618(05)80080-5

Schmid, L. C., Mittag, M., Poll, S., Steffen, J., Wagner, J., Geis, H. R., et al. (2016). Dysfunction of somatostatin-positive interneurons associated with memory deficits in an Alzheimers disease model. Neuron 92, 114-125. doi: 10.1016/j. neuron.2016.08.034

Serrano, A., Haddjeri, N., Lacaille, J.-C., and Robitaille, R. (2006). Gabaergic network activation of glial cells underlies hippocampal heterosynaptic depression. J. Neurosci. 16, 5073-5081. doi: 10.1523/JNEUROSCI.5255-05.2006

Sharma, V., Sood, R., Khlaifia, A., Eslamizade, M. J., Hung, T.-Y., Lou, D., et al. (2020). Eif $2 \alpha$ controls memory consolidation via excitatory and somatostatin neurons. Nature 586, 412-416. doi: 10.1038/s41586-020-2805-8

Sheffield, M. E., and Dombeck, D. A. (2019). Dendritic mechanisms of hippocampal place field formation. Curr. Opin. Neurobiol. 54, 1-11. doi: 10.1016/j.conb.2018.07.004

Sheffield, M. E. J., Adoff, M. D., and Dombeck, D. A. (2017). Increased prevalence of calcium transients across the dendritic arbor during place field formation. Neuron 96, 490-504.e5.doi: 10.1016/j.neuron.2017.09.029

Shigemoto, R., Kulik, A., Roberts, J. D. B., Ohishi, H., Nusser, Z., Kaneko, T., et al. (1996). Target-cell-specific concentration of a metabotropic glutamate receptor in the presynaptic active zone. Nature 381, 523-525. doi: 10.1038/38 $1523 \mathrm{a} 0$

Sik, A., Penttonen, M., and Buzsaki, G. (1997). Interneurons in the hippocampal dentate gyrus: an in vivo intracellular study. Eur. J. Neurosci. 9, 573-588. doi: 10.1111/j.1460-9568.1997.tb01634.x

Siwani, S., França, A. S. C., Mikulovic, S., Reis, A., Hilscher, M. M., Edwards, S. J., et al. (2018). Olm $\alpha 2$ cells bidirectionally modulate learning. Neuron 99 , 404.e3-412.e3.doi: 10.1016/j.neuron.2018.06.022

Somogyi, P., and Klausberger, T. (2005). Defined types of cortical interneurone structure space and spike timing in the hippocampus. J. Physiol. 562, 9-26. doi: 10.1113/jphysiol.2004.078915

Somogyi, P., Katona, L., Klausberger, T., Lasztóczi, B., and Viney, T. J. (2014). Temporal redistribution of inhibition over neuronal subcellular domains underlies state-dependent rhythmic change of excitability in the hippocampus. Philos. Trans. R. Soc. Lond. B Biol. Sci. 369:2010518. doi: 10.1098/rstb. 2012.0518

Stefanelli, T., Bertollini, C., Lüscher, C., Muller, D., and Mendez, P. (2016). Hippocampal somatostatin interneurons control the size of neuronal memory ensembles. Neuron 89, 1074-1085. doi: 10.1016/j.neuron.2016.01.024

Sun, Y., Nguyen, A. Q., Nguyen, J. P., Le, L., Saur, D., Choi, J., et al. (2014). Cell-type-specific circuit connectivity of hippocampal Cal revealed through 
cre-dependent rabies tracing. Cell Rep. 7, 269-280. doi: 10.1016/j.celrep.2014. 02.030

Sylwestrak, E. L., and Ghosh, A. (2012). Elfn1 regulates target-specific release probability at Cal-interneuron synapses. Science 338, 536-540. doi: $10.1126 /$ science. 1222482

Szonyi, A., Sos, K. E., Nyilas, R., Schlingloff, D., Domonkos, A., Takacs, V. T., et al. (2019). Brainstem nucleus incertus controls contextual memory formation. Science 364:eaaw0445. doi: 10.1126/science.aaw0445

Takahashi, H., and Magee, J. C. (2009). Pathway interactions and synaptic plasticity in the dendritic tuft regions of Ca1 pyramidal neurons. Neuron 62, 102-111. doi: 10.1016/j.neuron.2009.03.007

Tallent, M. K., and Siggins, G. R. (1997). Somatostatin depresses excitatory but not inhibitory neurotransmission in rat Cal hippocampus. J. Neurophysiol. 78, 3008-3018. doi: 10.1152/jn.1997.78.6.3008

Tan, Z., Liu, Y., Xi, W., Lou, H. F., Zhu, L., Guo, Z., et al. (2017). Glia-derived atp inversely regulates excitability of pyramidal and cck-positive neurons. Nat. Commun. 8:13772. doi: $10.1038 /$ ncomms 13772

Tonegawa, S., Mark, D. M., and Kitamura, T. (2018). The role of engram cells in the systems consolidation of memory. Nat. Neurosci. 19, 485-498. doi: 10.1038/s41583-018-0031-2

Tong, L. M., Djukic, B., Arnold, C., Gillespie, A. K., Yoon, S. Y., Wang, M. M., et al. (2014). Inhibitory interneuron progenitor transplantation restores normal learning and memory in APOe4 knock-in mice without or with abeta accumulation. J. Neurosci. 34, 9506-9515. doi: 10.1523/JNEUROSCI.069314.2014

Topolnik, L., Azzi, M., Morin, F., Kougioumoutzakis, A., and Lacaille, J. C. (2006). Mglur1/5 subtype-specific calcium signaling and induction of long-term potentiation in rat hippocampal oriens/alveus interneurones. J. Physiol. 575, 115-131. doi: 10.1113/jphysiol.2006.112896

Topolnik, L., Chamberland, S., Pelletier, J. G., Ran, I., and Lacaille, J. C. (2009). Activity-dependent compartmentalized regulation of dendritic $\mathrm{Ca}^{2+}$ signaling in hippocampal interneurons. J. Neurosci. 29, 4658-4663. doi: 10.1523/JNEUROSCI.0493-09.2009

Topolnik, L., Congar, P., and Lacaille, J. C. (2005). Differential regulation of metabotropic glutamate receptor- and ampa receptor-mediated dendritic $\mathrm{Ca}^{2+}$ signals by presynaptic and postsynaptic activity in hippocampal interneurons. J. Neurosci. 25, 990-1001. doi: 10.1523/JNEUROSCI.4388-04.2005

Toth, K., and McBain, C. J. (1998). Afferent-specific innervation of two distinct ampa receptor subtypes on single hippocampal interneurons. Nat. Neurosci. 1, 572-578. doi: 10.1038/2807

Tricoire, L., Pelkey, K. A., Erkkila, B. E., Jeffries, B. W., Yuan, X., and McBain, C. J. (2011). A blueprint for the spatiotemporal origins of mouse hippocampal interneuron diversity. J. Neurosci. 31, 10948-10970. doi: 10.1523/JNEUROSCI. 0323-11.2011

Tukker, J. J., Fuentealba, P., Hartwich, K., Somogyi, P., and Klausberger, T. (2007). Cell type-specific tuning of hippocampal interneuron firing during gamma oscillations in vivo. J. Neurosci. 27, 8184-8189. doi: 10.1523/JNEUROSCI.168507.2007

Tyan, L., Chamberland, S., Magnin, E., Camiré, O., Francavilla, R., David, L. S., et al. (2014). Dendritic inhibition provided by interneuron-specific cells controls the firing rate and timing of the hippocampal feedback inhibitory circuitry. J. Neurosci. 34, 4534-4547. doi: 10.1523/JNEUROSCI.3813-13.2014

Udakis, M., Pedrosa, V., Chamberlain, S. E. L., Clopath, C., and Mellor, J. R. (2020). Interneuron-specific plasticity at parvalbumin and somatostatin inhibitory synapses onto Cal pyramidal neurons shapes hippocampal output. Nat. Commun. 11:4395. doi: 10.1038/s41467-020-18074-8

Unal, G., Crump, M. G., Viney, T. J., Éltes, T., Katona, L., Klausberger, T., et al. (2018). Spatio-temporal specialization of gabaergic septo-hippocampal neurons for rhythmic network activity. Brain Struct. Funct. 223, 2409-2432. doi: 10.1007/s00429-018-1626-0

Vanderwolf, C. H. (1969). Hippocampal electrical activity and voluntary movement in the rat. Electroencephalogr. Clin. Neurophysiol. 26, 407-418. doi: 10.1016/0013-4694(69)90092-3
Varga, C., Golshani, P., and Soltesz, I. (2012). Frequency-invariant temporal ordering of interneuronal discharges during hippocampal oscillations in awake mice. Proc. Natl. Acad. Sci. U S A 109, E2726-E2734. doi: 10.1073/pnas. 1210929109

Vasuta, C., Artinian, J., Laplante, I., Hebert-Seropian, S., Elayoubi, K., and Lacaille, J.-C. (2015). Metaplastic regulation of Cal schaffer collateral pathway plasticity by hebbian mglurla-mediated plasticity at excitatory synapses onto somatostatin-expressing interneurons. eNeuro 2:ENEURO.0051-15.2015. doi: 10.1523/ENEURO.0051-15.2015

Vécsei, L., and Widerlöv, E. (1988). Effects of intracerebroventricularly administered somatostatin on passive avoidance, shuttle-box behavior and open-field activity in rats. Neuropeptides 12, 237-242. doi: 10.1016/01434179(88)90061-3

Vécsei, L., Király, C., Bollók, I., Nagy, A., Varga, J., Penke, B., et al. (1984). Comparative studies with somatostatin and cysteamine in different behavioral tests on rats. Pharmacol. Biochem. Behav. 21, 833-837. doi: 10.1016/s00913057(84)80061-1

Vécsei, L., Pavo, I., Zsigo, J., Penke, B., and Widerlöv, E. (1989). Comparative studies of somatostatin-14 and some of its fragments on passive avoidance behavior, open field activity and on barrel rotation phenomenon in rats. Peptides 10, 1153-1157. doi: 10.1016/0196-9781(89)90007-7

Vezzani, A., Ruiz, R., Monno, A., Rizzi, M., Lindefors, N., Samanin, R., et al. (1993). Extracellular somatostatin measured by microdialysis in the hippocampus of freely moving rats: evidence for neuronal release. J. Neurochem. 60, 671-677. doi: 10.1111/j.1471-4159.1993.tb03200.x

Villette, V., Poindessous-Jazat, F., Simon, A., Lena, C., Roullot, E., Bellessort, B., et al. (2010). Decreased rhythmic gabaergic septal activity and memoryassociated theta oscillations after hippocampal amyloid-beta pathology in the rat. J. Neurosci. 30, 10991-11003. doi: 10.1523/JNEUROSCI.628409.2010

Wang, J., Dickson, D. W., Trojanowski, J. Q., and Lee, V. M.-Y. (1999). The levels of soluble versus insoluble brain a $\beta$ distinguish Alzheimers disease from normal and pathologic aging. Exp. Neurol. 158, 328-337. doi: 10.1006/exnr. 1999.7085

Wei, W., Nguyen, L. N., Kessels, H. W., Hagiwara, H., Sisodia, S., and Malinow, R. (2010). Amyloid beta from axons and dendrites reduces local spine number and plasticity. Nat. Neurosci. 13, 190-196. doi: 10.1038/nn.2476

Wierenga, C. J., and Wadman, W. J. (2003). Excitatory inputs to Cal interneurons show selective synaptic dynamics. J. Neurophysiol. 90, 811-821. doi: 10.1152/jn. 00865.2002

Wigstrom, H., and Gustafsson, B. (1983). Facilitated induction of hippocampal long-lasting potentiation during blockade of inhibition. Nature 301, 603-604. doi: 10.1038/301603a0

Yoon, B.-E., Jo, S., Woo, J., Lee, J.-H., Kim, T., Kim, D., et al. (2011). The amount of astrocytic gaba positively correlates with the degree of tonic inhibition in hippocampal Ca1 and cerebellum. Mol. Brain 4, 1-7. doi: 10.1186/1756-66 06-4-42

Yuan, M., Meyer, T., Benkowitz, C., Savanthrapadian, S., Ansel-Bollepalli, L., Foggetti, A., et al. (2017). Somatostatin-positive interneurons in the dentate gyrus of mice provide local- and long-range septal synaptic inhibition. eLife 6:e21105. doi: 10.7554/eLife.21105

Conflict of Interest: The authors declare that the research was conducted in the absence of any commercial or financial relationships that could be construed as a potential conflict of interest.

Copyright $\odot 2021$ Honoré, Khlaifia, Bosson and Lacaille. This is an open-access article distributed under the terms of the Creative Commons Attribution License (CC BY). The use, distribution or reproduction in other forums is permitted, provided the original author(s) and the copyright owner(s) are credited and that the original publication in this journal is cited, in accordance with accepted academic practice. No use, distribution or reproduction is permitted which does not comply with these terms. 